\title{
Mouse endogenous retroviruses can trigger premature transcriptional termination at a distance
}

\author{
Jingfeng Li, ${ }^{1}$ Keiko Akagi, ${ }^{1}$ Yongjun Hu, ${ }^{2}$ Anna L. Trivett, ${ }^{3}$ Christopher J.W. Hlynialuk, ${ }^{1}$ \\ Deborah A. Swing, ${ }^{4}$ Natalia Volfovsky, ${ }^{5}$ Tamara C. Morgan, ${ }^{6}$ Yelena Golubeva, ${ }^{6}$ \\ Robert M. Stephens, ${ }^{5}$ David E. Smith, ${ }^{2}$ and David E. Symer ${ }^{1,7,8}$
}

${ }^{1}$ Human Cancer Genetics Program and Department of Molecular Virology, Immunology and Medical Genetics, The Ohio State University Comprehensive Cancer Center, Columbus, Ohio 43210, USA; ${ }^{2}$ Department of Pharmaceutical Sciences, University of Michigan, Ann Arbor, Michigan 48109, USA; ${ }^{3}$ Laboratory of Molecular Immunoregulation and ${ }^{4}$ Mouse Cancer Genetics Program, National Cancer Institute, Frederick, Maryland 21702, USA; ${ }^{5}$ Advanced Biomedical Computing Center, Information Systems Program and ${ }^{6}$ Histotechnology Laboratory, SAIC-Frederick, Inc., National Cancer Institute, Frederick, Maryland 21702, USA; ${ }^{7}$ Department of Internal Medicine and Department of Biomedical Informatics, The Ohio State University Comprehensive Cancer Center, Columbus, Ohio 43210, USA

\begin{abstract}
Endogenous retrotransposons have caused extensive genomic variation within mammalian species, but the functional implications of such mobilization are mostly unknown. We mapped thousands of endogenous retrovirus (ERV) germline integrants in highly divergent, previously unsequenced mouse lineages, facilitating a comparison of gene expression in the presence or absence of local insertions. Polymorphic ERVs occur relatively infrequently in gene introns and are particularly depleted from genes involved in embryogenesis or that are highly expressed in embryonic stem cells. Their genomic distribution implies ongoing negative selection due to deleterious effects on gene expression and function. A polymorphic, intronic ERV at SIc15a2 triggers up to 49-fold increases in premature transcriptional termination and up to 39-fold reductions in full-length transcripts in adult mouse tissues, thereby disrupting protein expression and functional activity. Prematurely truncated transcripts also occur at Polrla, Sponl, and up to $\sim 5 \%$ of other genes when intronic ERV polymorphisms are present. Analysis of expression quantitative trait loci (eQTLs) in recombinant BxD mouse strains demonstrated very strong genetic associations between the polymorphic ERV in cis and disrupted transcript levels. Premature polyadenylation is triggered at genomic distances up to $>12.5 \mathrm{~kb}$ upstream of the ERV, both in cis and between alleles. The parent of origin of the ERV is associated with variable expression of nonterminated transcripts and differential DNA methylation at its 5 -long terminal repeat. This study defines an unexpectedly strong functional impact of ERVs in disrupting gene transcription at a distance and demonstrates that ongoing retrotransposition can contribute significantly to natural phenotypic diversity.
\end{abstract}

[Supplemental material is available for this article.]

The laboratory mouse is the premier model organism, facilitating comparative studies of human diseases, development, and natural variation. Numerous distinct mouse lineages manifest phenotypic differences such as various coat colors and differential susceptibilities to diseases (Wade and Daly 2005). The molecular basis for natural phenotypic variation or allele-specific expression differences remains unclear in most cases, although recent studies have associated differential gene expression with various forms of structural variation in mouse and human genomes (Yan et al. 2002; Adams et al. 2005; Yang et al. 2007; She et al. 2008; Cahan et al. 2009; Schlattl et al. 2011; Yalcin et al. 2011).

Transposons are a potentially major but relatively unexamined determinant of such allele-specific, transcriptional variation. They are strong candidates for regulating or disrupting gene expression since they comprise almost half of the mouse genome and certain elements are still actively mobilized. Approximately $10 \%$ of naturally occurring mutations in the mouse have been attributed to insertional mutagenesis of coding sequences due to

\section{${ }^{8}$ Corresponding author.}

E-mail david.symer@osumc.edu.

Article published online before print. Article, supplemental material, and publication date are at http://www.genome.org/cgi/doi/10.1101/gr.130740.111. endogenous retrotransposition (Waterston et al. 2002). We recently showed that thousands of polymorphic retrotransposon integrants of various active classes are present in the C57BL/6J (hereafter abbreviated as B6) reference genome but absent from one or more other classical inbred mouse lineages (i.e., A/J; DBA/2J, DBA; 129S1/SvImJ, 129S1; and 129X1/SvJ, 129X1) (Akagi et al. 2008). Of these, new endogenous retrovirus (ERV)-K integrants may be particularly capable of altering transcriptomes in diverse tissues (van de Lagemaat et al. 2003; Medstrand et al. 2005). Members of various ERV families make up $\sim 10 \%$ of the mouse genome. While most such genomic elements are ancient and are comprised of solo long terminal repeats (LTRs), the ERV-K family includes a significant number of young full-length elements flanked by virtually identical LTRs. Of these, intracisternal A-particle (IAP) retrotransposons are still capable of autonomous mobilization and are transcriptionally activated by genome-wide cytosine demethylation (Walsh et al. 1998), contributing to tumor formation (Howard et al. 2007). Approximately 1000 of these elements contain intact open reading frames (ORFs). They have long been known to be active and polymorphic in various mouse lineages and tumors (Shen-Ong and Cole 1982; Lueders et al. 1993; Zhang et al. 2008). To simplify nomenclature, we refer to these IAP retrotransposons as ERVs. 
Well-characterized retrotransposon integrants that alter gene expression and mediate phenotypic variability include the dilute and hairless coat color mutations (Copeland et al. 1983; Stoye et al. 1988). In these cases, intronic murine leukemia virus (MLV) insertions cause aberrant splicing of overlapping gene transcripts. MLV sequences are incorporated directly at the 3' ends of disrupted transcripts, which are then prematurely terminated (Seperack et al. 1995; Cachon-Gonzalez et al. 1999). In contrast, ERV (IAP) integrants upstream of or within the $A$ (i.e., agouti) and $A x i n 1$ (i.e., axin 1) genes inserted active, heterologous promoters in the resulting agouti viable yellow $\left(A^{v y}\right)$ and axin fused $\left(A x i n 1^{F u}\right)$ alleles, resulting in epigenetically regulated, variable initiation of downstream fusion transcripts (Morgan et al. 1999; Whitelaw and Martin 2001). Fulllength ERV integrants also can affect neighboring gene transcription by direct incorporation of polyadenylation signal sequences and/or binding sites for transcription factors (van de Lagemaat et al. 2003; Medstrand et al. 2005), as was observed recently for Adamts13 (i.e., a disintegrin-like and metallopeptidase [reprolysin type] with thrombospondin type 1 motif, 13), a von Willebrand factor-cleaving protease disrupted by an intronic ERV integrant (Banno et al. 2004; Zhou et al. 2007). However, until now, other effects by ERV polymorphisms have not been characterized. To associate variable gene expression levels with the presence or absence of local ERV insertions, we mapped ERVs in several highly divergent mouse lineages. We then identified and characterized numerous cases in which gene transcripts are strongly and differentially disrupted at a distance by nearby ERV polymorphisms.

\section{Results}

Identification of polymorphic ERVs in diverse mouse strains by transposon junction assay

To study possible effects of ERV integrants on neighboring gene expression levels, first we mapped such integrants in previously unsequenced, diverse mouse strains, without prior knowledge of their location or polymorphism status. Recently, various methods to find ERV insertions, both polymorphic and nonpolymorphic, have been described (Horie et al. 2007; Akagi et al. 2008; Takabatake et al. 2008; Zhang et al. 2008; Qin et al. 2010; Ray et al. 2011). We developed and optimized a sensitive, high-resolution genomic mapping assay using PCR and 454 Life Sciences (Roche) sequencing, which we call the transposon junction assay (Supplemental Fig. 1; Pornthanakasem and Mutirangura 2004; Iskow et al. 2010; Witherspoon et al. 2010). Using transposon sequence-specific and degenerate primers for genomic PCR amplification, we targeted members of certain young ERV families including IAPLTR1, IAPLTR2, and IAPEY2 elements (Kapitonov and Jurka 2008) since they are anticipated to be polymorphic (Qin et al. 2010) in diverse mouse lineages. Based on their features observed in the reference B6 genome, the IAPLTR1 integrants are most likely to be full length and to have identical LTRs (data not shown), consistent with their status as the youngest ERV insertions (Qin et al. 2010).

We optimized the transposon junction assay using various combinations of restriction enzymes and degenerate primers (Supplemental Table 1). This method reidentified 1538 out of 1665 (92.4\%) of the youngest mappable ERV (IAPLTR1) integrants in the reference $\mathrm{B} 6$ genome at $\sim 14$-fold sequencing coverage. To validate these results, we compared chromosomal distributions of identified ERVs with previously annotated reference elements (Supplemental Fig. 1). Overall, the correlation between local densities of reference versus resequenced transposon integrants is excellent, particularly for IAPLTR1 elements $\left(p<2.2 \times 10^{-16}\right)$. Pearson's correlation coefficients are 0.75 (IAPLTR1), 0.78 (IAPLTR2), and 0.60 (IAPEY2). Thus no significant global bias was detected in identifying ERVK elements by targeted resequencing.

We used this assay to define the genomic locations of young ERVs in six diverse mouse lineages, i.e., A/J, B6, CAST/EiJ (CAST), MOLF/EiJ (MOLF), SPRET/EiJ (SPRET), and WSB/EiJ (WSB); 25,069 integrants were identified (Supplemental Table 1). The chromosomal integration sites of IAPLTR1 integrants are almost entirely different in comparing the highly divergent, wild mouse lineages (SPRET, CAST, and MOLF), because only four out of several thousand IAPLTR1 integrants are present at orthologous loci (Fig. 1). This result strongly suggests that the rare, shared integrants are 
identical by descent (Salem et al. 2005; Ray et al. 2011) and reveals extensive, lineage-specific retrotransposition. As expected, they are conserved at higher frequencies at orthologous loci in the related classical lines (B6, A/J, and WSB). Additionally, our bioinformatics analysis identified thousands of additional, previously unreported ERV polymorphisms that are present in one or more of the nonreference "Celera strains," i.e., A/J, DBA, 129S1, and 129X1 mice (Akagi et al. 2008) but absent from the B6 reference genome. Very similar proportions of polymorphic retrotransposon families including ERVs are present or absent in these strains, regardless of the genome chosen for comparison (Supplemental Fig. 2).

To compare the chromosomal distributions of polymorphic versus nonpolymorphic ERVs in various lineages, we plotted the number of elements counted in $10-\mathrm{Mb}$ genomic intervals in single versus additional strains (Fig. 1C). IAPLTR1 integrants are mostly present in only one of the six diverse strains studied here; they are highly polymorphic. When their counts are summed up across the different strains, the polymorphic integrants are quite uniformly distributed across the genome, without large hotspot or desert regions in the chromosomes. In contrast, older IAPLTR2 and particularly IAPEY2 integrants tend to be more nonpolymorphic in multiple diverse strains. Both reference and polymorphic ERV integrants are more uniformly distributed across the genome than are reference and polymorphic L1 retrotransposons (Supplemental Fig. 2; Akagi et al. 2008).

We validated a collection of ERV integrants identified here, by amplifying occupied or empty genomic target sites in up to 21 diverse mouse lineages using PCR (Supplemental Fig. 1; Supplemental Tables 2, 3). The results demonstrate that both the transposon junction assay and our analysis of Celera sequence traces (Akagi et al. 2008) accurately determine the presence of integrants, and confirm that ERV insertions are extremely polymorphic (Zhang et al. 2008). Recent whole-genome shotgun (WGS) sequencing of 17 mouse strains has facilitated identification of thousands more retrotransposon polymorphisms (Keane et al. 2011; Yalcin et al. 2011). We compared ERVs mapped by the transposon junction assay, PCR validation, and WGS predictions. Out of 140 verifiable integrants called by the transposon junction assay, 135 (>96\%) were validated both by PCR and by WGS sequencing (Supplemental Table 2). In four of the five discrepant cases, our transposon junction assay and confirming PCR indicated empty target sites, but WGS demonstrated the presence of ERV integrants. These cases indicate that the genomic DNA samples used in our assays versus WGS sequencing are likely to include bona fide sequence differences of unknown cause.

\section{Genomic distribution of polymorphic ERVs suggests deleterious impact on gene expression}

We assessed the genomic locations of young ERV polymorphisms relative to annotated genes, since their existing distribution would reflect insertion preferences and/or losses of deleterious elements. All classes of young ERV polymorphisms occur in gene introns at lower densities than expected from a simulated pattern of insertions due solely to chance (Fig. 2; Table 1). They are even more strongly depleted from particular genes involved in embryogenesis and/or highly expressed in embryonic stem (ES) cells (Fig. 2; Mikkelsen et al. 2007). The oldest ERVs mapped here, IAPEY2 elements, occur at even lower densities in intragenic locations than younger IAPs such as LTR1 and LTR2. Of the ERVs within genes, $\sim 72 \%-83 \%$ are oriented antiparallel to the sense (coding) strand of the genes, rather than the 50/50 orientation frequency expected if
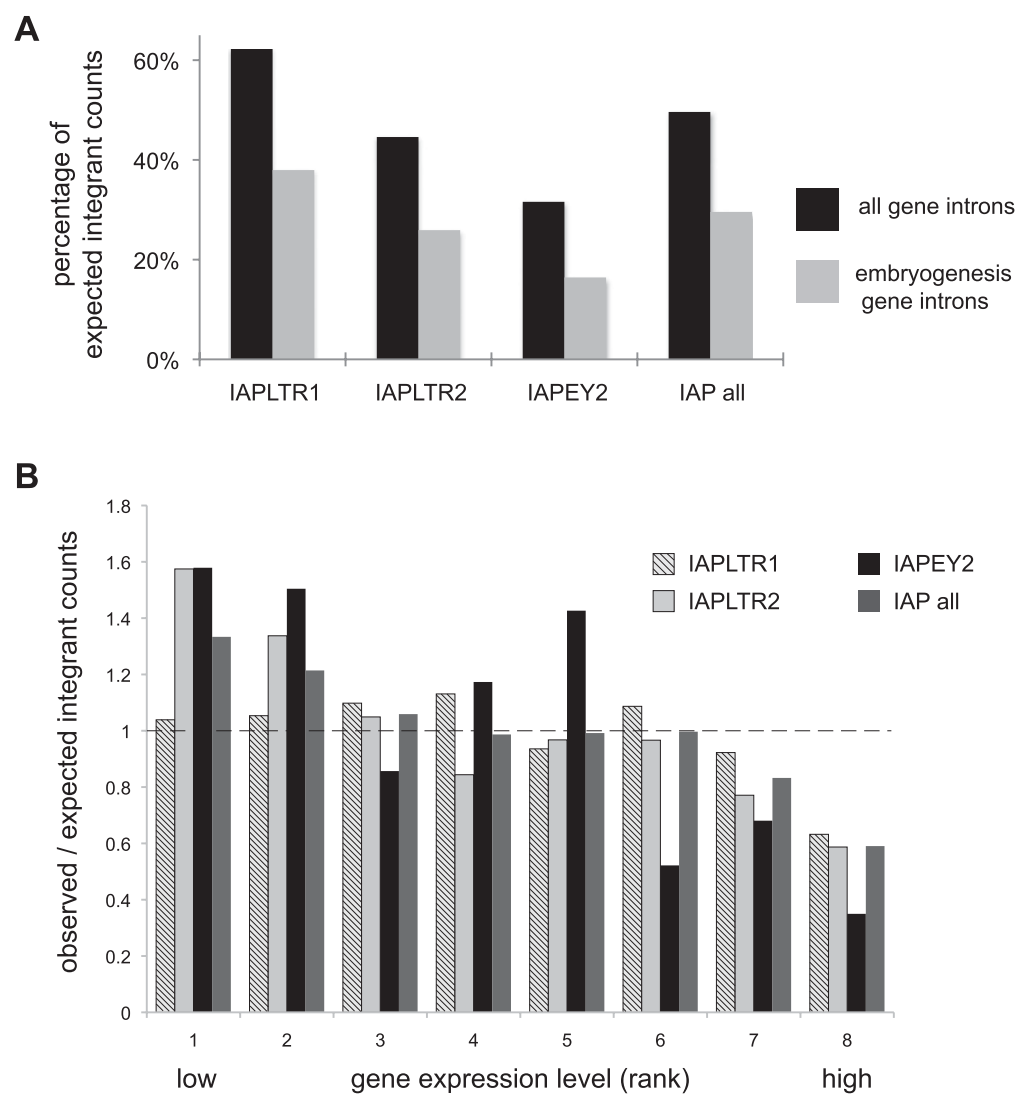

Figure 2. Young ERVs are excluded from introns, particularly from embryogenesis and highly expressed genes. (A) "Observed" ERV integrant counts are plotted as percentages of "expected" counts within all gene introns (black histograms) or embryogenesis genes (gray). Genomic locations of various classes of ERVs ( $x$-axis) were identified in diverse mouse lineages. Expected counts were determined by random simulation of 2 million insertion sites across the reference genome. By chance, $\sim 35 \%$ of ERV insertions would be expected to fall within RefSeq gene introns, and $\sim 2.7 \%$ of all insertions would fall within embryogenesis genes, defined by the Mouse Genome Informatics database (http://www.informatics.jax.org). This normalization corrects for gene lengths. Percentages $<100 \%$ signify relative exclusion of certain ERV subtypes from particular gene categories. (B) Based on their expression levels in mouse ES cells measured by microarrays (Mikkelsen et al. 2007), genes were binned into eight groups ranked from 1 (lowest expression) to 8 (highest), each with roughly equivalent numbers of genes expressed at comparable levels. Ratios of the observed numbers of genes containing intronic ERV integrants versus the expected number of genes identified by random simulation are presented (Brady et al. 2009) for different classes of ERV integrants (key, upper right). (Dashed line) Ratio $=1$ signifies equivalence between observed and expected counts; ratios $<1$ signify relative exclusion of ERV integrants from particular groups of genes. 
Table 1. Young ERVs occur at low densities in gene introns

\begin{tabular}{lrrrrr}
\hline & $\begin{array}{c}\text { Number of } \\
\text { elements }\end{array}$ & $\begin{array}{c}\text { Number of } \\
\text { intronic } \\
\text { elements }\end{array}$ & \% intronic & $\begin{array}{c}\text { Number of } \\
\text { sense oriented, } \\
\text { intronic }\end{array}$ & $\begin{array}{c}\% \text { sense } \\
\text { oriented, } \\
\text { intronic }\end{array}$ \\
\hline $\begin{array}{l}\text { Reference ERV class } \\
\text { IAPLTR1 }\end{array}$ & 4410 & & & & \\
IAPLTR2 & 5772 & 961 & $21.8 \%$ & 256 & $26.6 \%$ \\
IAPEY2 & 1112 & 123 & $15.6 \%$ & 235 & $26.1 \%$ \\
All ref IAP & 11,661 & 2026 & $11.1 \%$ & 21 & $17.1 \%$ \\
Simulation & $2,000,000$ & 700,262 & $35.0 \%$ & 349,896 & $50.0 \%$ \\
& & & & & \\
Nonreference ERV class & 2789 & 622 & $22.3 \%$ & 164 & $26.4 \%$ \\
IAPLTR1 & 3494 & 585 & $16.7 \%$ & 161 & $27.5 \%$ \\
IAPLTR2 & 501 & 58 & $11.6 \%$ & 15 & $25.9 \%$ \\
IAPEY2 & 7002 & 1291 & $18.4 \%$ & 342 & $26.5 \%$ \\
All non-ref IAP & $2,000,000$ & 700,262 & $35.0 \%$ & 349,896 & $50.0 \%$ \\
Simulation & & & & & \\
\hline
\end{tabular}

Summary of ERV elements identified in (top) B6 reference genome and (bottom) from combined analysis by transposon junction assay and bioinformatics analysis of A/J, DBA, 129S1, 129X1, WSB, SPRET, CAST, and MOLF mouse lineages. (Simulation) As a control, we simulated ERV insertions randomly throughout the reference genome. The results show strong biases against intronic insertions, particularly of the older IAPEY2 elements, and against elements positioned in the same orientation as gene open reading frames (i.e., sense orientation).

integration and retention of ERVs were due to chance (Table 1). This orientation bias has been observed previously (Smit 1999; Medstrand et al. 2002; van de Lagemaat et al. 2006; Zhang et al. 2008). It plausibly could reflect patterns of de novo integration, but new ERV integrants in mouse, human, and chicken do not display such orientation bias (Dewannieux et al. 2004; Barr et al. 2005; Brady et al. 2009). The relative lack both of genomic ERV integrants within transcribed genes and of sense-oriented intragenic integrants presumably reflects strong ongoing purifying selection against them, due to their putative deleterious consequences on gene expression, structure, and function. Genes that lack such ERV integrants across all lineages are likely to be functionally essential in early development and viability of the organism. Alternatively, current patterns of insertions could reflect de novo integration preferences, but this possibility is refuted by the finding that older ERV integrants occur at even lower densities in gene introns. Together, these results strongly suggest that ERV integrants can exert deleterious effects on gene expression and function, and therefore the remaining extant integrants are relatively absent from gene introns.

\section{An intronic ERV in SIc15a2 disrupts transcription, protein expression, and function}

The identification of thousands of polymorphic, intronic ERVs in diverse mouse strains provided a unique opportunity to assess their roles in transcriptional and functional variation, by comparing gene expression and functions in strains with and without such individual integrants. We first screened a collection of genes containing intronic ERVs by using reverse transcriptase-mediated polymerase chain reaction (RT-PCR) to identify fusion transcripts initiated from upstream polymorphic ERV promoters (Wheelan et al. 2005). We identified spliced downstream fusion transcripts initiated from intronic ERVs in Slc15a2 (i.e., solute carrier family $15\left[\mathrm{H}^{+} /\right.$peptide transporter], member 2 ) and Polr1a (i.e., polymerase [RNA] I polypeptide A) among others, expressed in a tissuespecific manner (data not shown). We designate such polymorphic integrants as $\mathrm{ERV}_{\text {Slc15a2 }}, \mathrm{ERV}_{\text {Polr1a }}$, etc.
To assess whether additional Slc15a2 transcriptional variants are associated with the presence or absence of $\mathrm{ERV}_{\text {Slc15a2, we }}$ probed RNA blots using cDNA probes generated from both $5^{\prime}$ and $3^{\prime}$ ends of conventional, full-length Slc15a2 transcripts (Fig. 3). Contrary to our initial RT-PCR results, the ERV-Slc15a2 downstream fusion transcript is not abundantly expressed, as shown by Northern blot using a $3^{\prime}$ probe (Fig. 3A). However, both $5^{\prime}$ and $3^{\prime}$ probes demonstrated that the presence of $\mathrm{ERV}_{\text {Slc15a2 }}$ in intron 7 is strongly associated with premature transcriptional termination, resulting in up to 39 -fold reductions in full-length $4-\mathrm{kb}$ transcripts and concomitant increases of up to 13 -fold or more of prematurely truncated 1.2-kb transcripts (Fig. 3A). These very significant changes in transcript structures and levels were observed in several tissues including brain and kidney. Notably, the prematurely truncated transcripts are expressed strongly only in strains harboring $\mathrm{ERV}_{\text {Slc15a2, }}$ confirmed by quantitative reverse transcriptasemediated PCR (qRT-PCR) and expression microarray assays (Supplemental Fig. 3).

Slc15a2 encodes PEPT2, a well-studied transporter of peptidelike molecules that is expressed in mouse brain, choroid plexus, kidney, lung, breast, and eye. PEPT2 has significant biological importance since it transports pharmacologic agents such as betalactam antibiotics in the kidney and brain (Brandsch et al. 2008), protects against 5-aminolevulinic acid neurotoxicity ( $\mathrm{Hu}$ et al. 2007), and reduces the analgesic effect of L-kyotorphin (Jiang et al. 2009). While Slc15a2 experimental knockout mice are viable and fertile, their physiological transport of certain oligopeptides is disrupted (Shen et al. 2003; Smith et al. 2011).

The ERV-associated transcriptional disruption results in approximately threefold to ninefold reductions in protein expression in each individual B6 mouse tested, when compared with DBA/2J

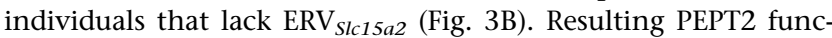
tional peptide transport activity is also significantly reduced in B6 brain and lung compared with DBA/2J tissues (Fig. 3C). Thus, significant functional variation between the mouse strains is strongly associated with the presence or absence of an intronic ERV integrant within this genetic locus.

The truncated Slc15a2 transcript also was detected in strains lacking $\mathrm{ERV}_{\text {Slc15a2, }}$ albeit at very low levels, upon prolonged exposure of Northern blots (Fig. 4A). This prematurely truncated transcript does not terminate inside $\mathrm{ERV}_{\text {Slc15a2 }}$ itself and includes no sequences templated by that ERV, in contrast to transcripts terminated within other intragenic transposable elements (Zhou et al. 2007; Zhang et al. 2008; Li et al. 2010). Instead, 3' rapid cloning of cDNA ends (rapid amplification of cDNA ends, RACE) experiments using adult brain total RNAs demonstrated that truncated Slc15a2 transcripts stop $\sim 1.5 \mathrm{~kb}$ upstream of ERV $\mathrm{Elc15a2}_{\text {, }}$ distal to the splice donor site at the $3^{\prime}$ end of exon 7 (GenBank accession numbers JF495121-JF495122) (Fig. 4B). Their 3' ends precisely match transcripts previously identified in mammary tissue, tumor, and in day 16 embryos from B6 and FVB mouse strains (GenBank accession numbers NM_001145899, BC018335, AK018393, and BC051199). Notably, two weak predicted polyadenylation signal sequences (Beaudoing and Gautheret 2001) 
A
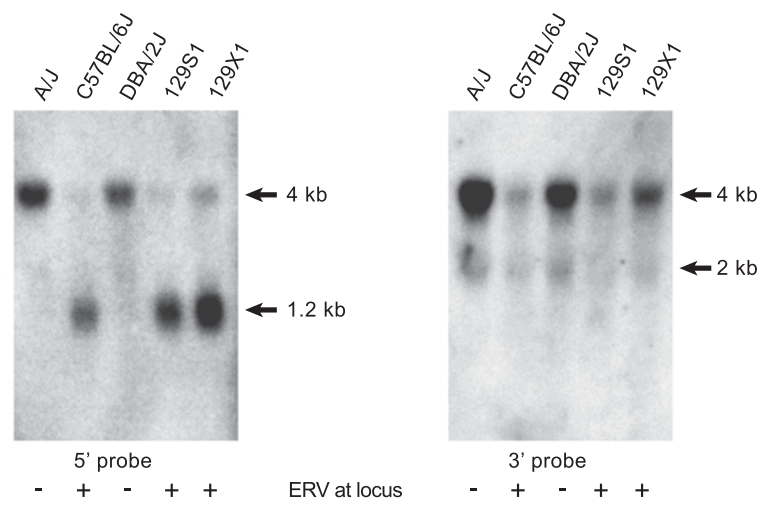

B
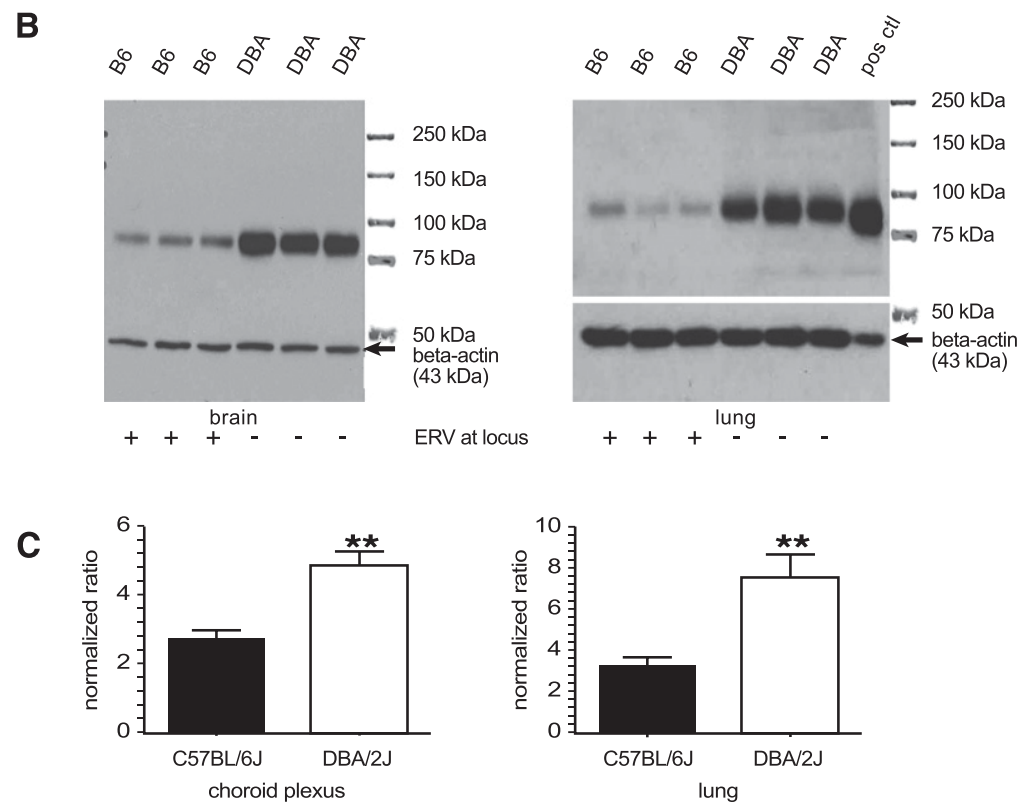

Figure 3. An intronic ERV polymorphism disrupts S/c15a2 expression and function. (A) Northern blots. Equivalent amounts ( $10 \mathrm{mcg}$ each) of total RNAs from brains pooled from several individuals from the indicated lineages were electrophoresed. Northern blots were probed with 5' (left) and 3' (right) probes from Slc15a2. (Left) Truncated transcripts (1.2 kb, arrow) correlate with the presence of a polymorphic ERV in B6, 129S1, and 129X1 strains but absent from the others. The full-length (nonterminated, $4 \mathrm{~kb}$ ) S/c15a2 transcript is expressed robustly in the absence of the ERV integrant in $\mathrm{A} / \mathrm{J}$ and DBA mice. (Right) No appreciable downstream fusion transcript $(2 \mathrm{~kb})$ was detected, although it was identified by qRT-PCR (data not shown). Loading controls are shown in Supplemental Figure 3A. (B) Western blots. Protein extracts from individual brains (left) and lungs (right) from B6 and DBA mice were electrophoresced and probed for PEPT2 using protein-specific antiserum. (C) Functional assay in vivo. Accumulation of radiolabeled Gly-Sar dipeptide substrate was measured in choroid plexus and lung from B6 versus DBA mouse lineages, indicating significantly different PEPT2 functional activities (asterisks). we could assess relationships between SNPs genome-wide and variable Slc15a2 transcription by considering both truncated and full-length transcripts as eQTLs. The results demonstrate a very strong association between the $\mathrm{ERV}_{\text {Slc15az-positive }}$ haplotype (as approximated by the closest informative SNP, rs4173858) and differential Slc15a2 expression, i.e., both truncated and full-length transcripts (Fig. 5). Almost all BxD RI lines that are $\mathrm{ERV}_{\text {Slc15a2}}$-positive express significantly more truncated Slc15a2 transcript and significantly less full-length transcripts (Fig. 5B, bottom, cf. probe sets 1, 2, and 3). A few discrepant BxD lineages have SNP genotypes that appear to contradict the Slc15a2 expression levels. These apparent discrepancies each were resolved by checking the absence/presence status of ERV $_{\text {Slc15a2 }}$ (Supplemental Fig. 4; data not shown), rather than the adjacent SNP surrogate. Thus the ERV genotypes are all strongly correlated with the expression levels measured in each BxD RI strain.

We resequenced $1 \mathrm{~kb}$ upstream of and downstream from the premature termination site in multiple mouse strains (data not shown), disclosing only a single, previously identified, nonsynonymous SNP within exon 6 that does not correlate either with differential Slc15a2 expression or with the polymorphic $\mathrm{ERV}_{\text {Slc15a2 }}$ integrant. Moreover, we compared $335 \mathrm{~kb}$ of adjacent genomic sequences in B6 versus DBA/2J wild-type genomes, thereby identifying 42 SNPs and seven small indel polymorphisms. None of these variants, other than ERV $_{\text {Slc15a2 }}$ itself, are located inside of known coding genes; they each are upstream, downstream, or within gene introns, or within noncoding genes. None are classified as deleterious. Thus we conclude that $\mathrm{ERV}_{\text {SIc15a2 }}$ itself is the genetic determinant of variable transcription of Slc15a2 in cis. occur in intron 7, i.e., 5'-GATAAA and 5'-ATTAAA, immediately downstream from exon 7 and and upstream of the premature, added poly(A) tails (Fig. 4B).

To strengthen the genetic association between ERV $_{\text {Slc15a2 }}$ and transcriptional disruption further, we analyzed Slc15a2 expression data collected in kidneys from 53 distinct recombinant inbred (RI) mouse strains. These mice were derived from intercrosses of B6 and DBA/2J lines (B6 $\times$ DBA intercrossed mouse, $\mathrm{BxD})$, resulting in a panel of highly recombinant mice with homozygosity at virtually every genetic locus, facilitating the identification of the genetic determinants of expression quantitative trait loci (eQTLs) (Chesler et al. 2005). Since B6 and DBA wild-type mice do and do not contain the $\mathrm{ERV}_{\text {Slc15a2 }}$ integrant, respectively,

\section{Effects of the heterozygous ERV's parent of origin}

To assess possible consequences of $\mathrm{ERV}_{\text {Slc15a2 }}$ heterozygosity on Slc15a2 expression, we reciprocally crossed homozygous strains with (B6) and without (CAST/EiJ, CAST) this ERV, respectively. These intercrosses resulted in $F_{1}$ offspring with ERV $_{\text {Slc15a2 }}$ integrants having either parent of origin. Nonterminated (i.e., presumably full-length) Slc15a2 transcripts are significantly reduced in heterozygous CAST $\times \mathrm{B}_{6} \mathrm{~F}_{1}$ offspring with paternally derived $\mathrm{ERV}_{\text {Slc15a2 }}$ (Fig. 6A,B). This reduction is comparable to that observed in homozygous B6 mice, rather than an intermediate level of expression as predicted from heterozygosity of the ERV. Thus, terminated Slc15a2 transcript expression is strongly associated 
A

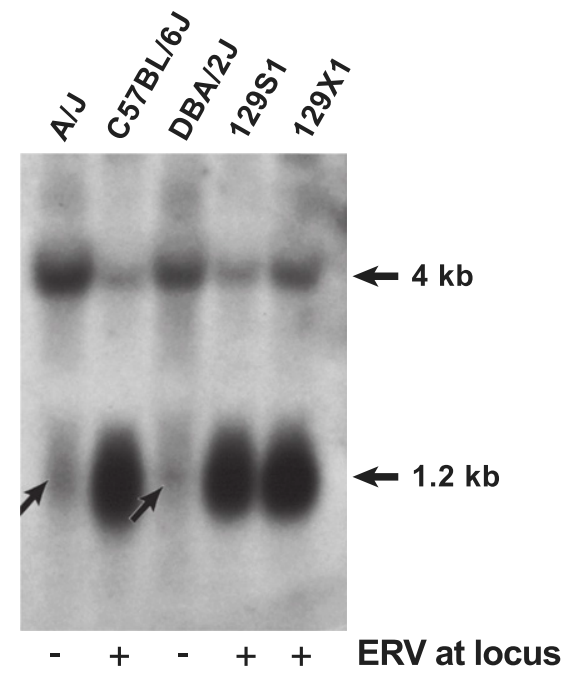

B
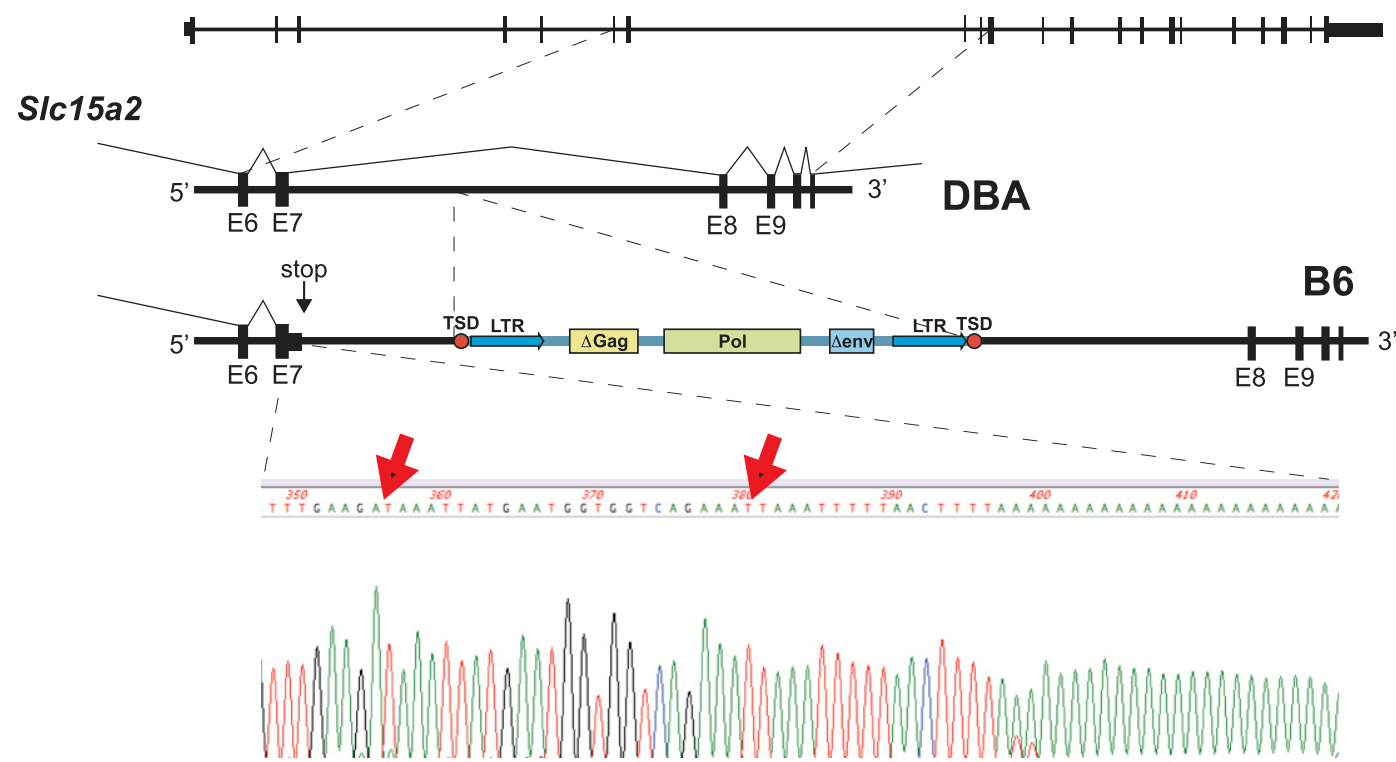

Figure 4. Transcriptional termination occurs at pre-existing signal upstream of ERV. (A) Prematurely terminated transcripts are present at low levels (arrows) in kidneys of mouse strains lacking the polymorphic ERV, indicating that the premature transcriptional polyadenylation signal exists both in strains that have or lack the ERV, and is not templated by the ERV per se. $(B$, top) Schematic of the SIC15a2 locus showing site of premature transcriptional termination $\sim 1.5 \mathrm{~kb}$ upstream of the intronic ERV polymorphism present in the B6 strain, in intron 7. (Bottom) Sequence trace from 3'-RACE experiment, demonstrating that the $3^{\prime}$ end of the prematurely truncated transcript is polyadenylated $\sim 1.5 \mathrm{~kb}$ upstream of the ERV and contains no ERV-templated sequences per se. (Red arrows) Weak pre-existing polyadenylation signals (i.e., 5'-GATAAA and ATTAAA) are present in the intron, immediately upstream of the added poly(A) tail. GenBank accession numbers JF495121-JF495122.

with the introduced intronic ERV; one $\left(\mathrm{ERV}^{+}\right)$allele can affect expression from the other $\left(\mathrm{ERV}^{-}\right)$. In contrast, $\mathrm{F}_{1}$ offspring with the maternally derived $\mathrm{ERV}_{\text {Slc15a2 }}$ allele exhibit robust expression of nonterminated Slc15a2 transcripts (Fig. 6A,B). In both crosses, we observed expression of both alleles at approximately equivalent levels (Supplemental Figs. 3 and 5). Thus the parent of origin of the $\mathrm{ERV}_{\text {Slc15a2 }}$ polymorphism affects the expression levels of nonterminated Slc15a2 transcripts in the offspring, and transcriptional disruption can occur between alleles.

In contrast to differential expression of full-length transcripts, the prematurely truncated $1.2-\mathrm{kb}$ transcript is detected at approx- imately equivalent, high levels in all mice that contain the ERV, much more than in strains lacking it (Fig. 6A,C). Notably, in some cases, the reduced expression of full-length transcripts is not correlated inversely with increased expression of prematurely truncated transcripts.

We sought to compare Slc15a2 expression levels in individual, age-matched mice with the same $\mathrm{ERV}_{\text {Slc15a2 }}$ genotypes but derived from different genetic backgrounds. Thus we set up additional genetic crosses of wild-type and $\mathrm{F}_{1}$ mice on both $\mathrm{B} 6$ and CAST genetic backgrounds, resulting in individual $F_{1}$ and $F_{2}$ offspring with all possible homozygous or heterozygous $\mathrm{ERV}_{\text {Slc15a2 }}$ geno- 

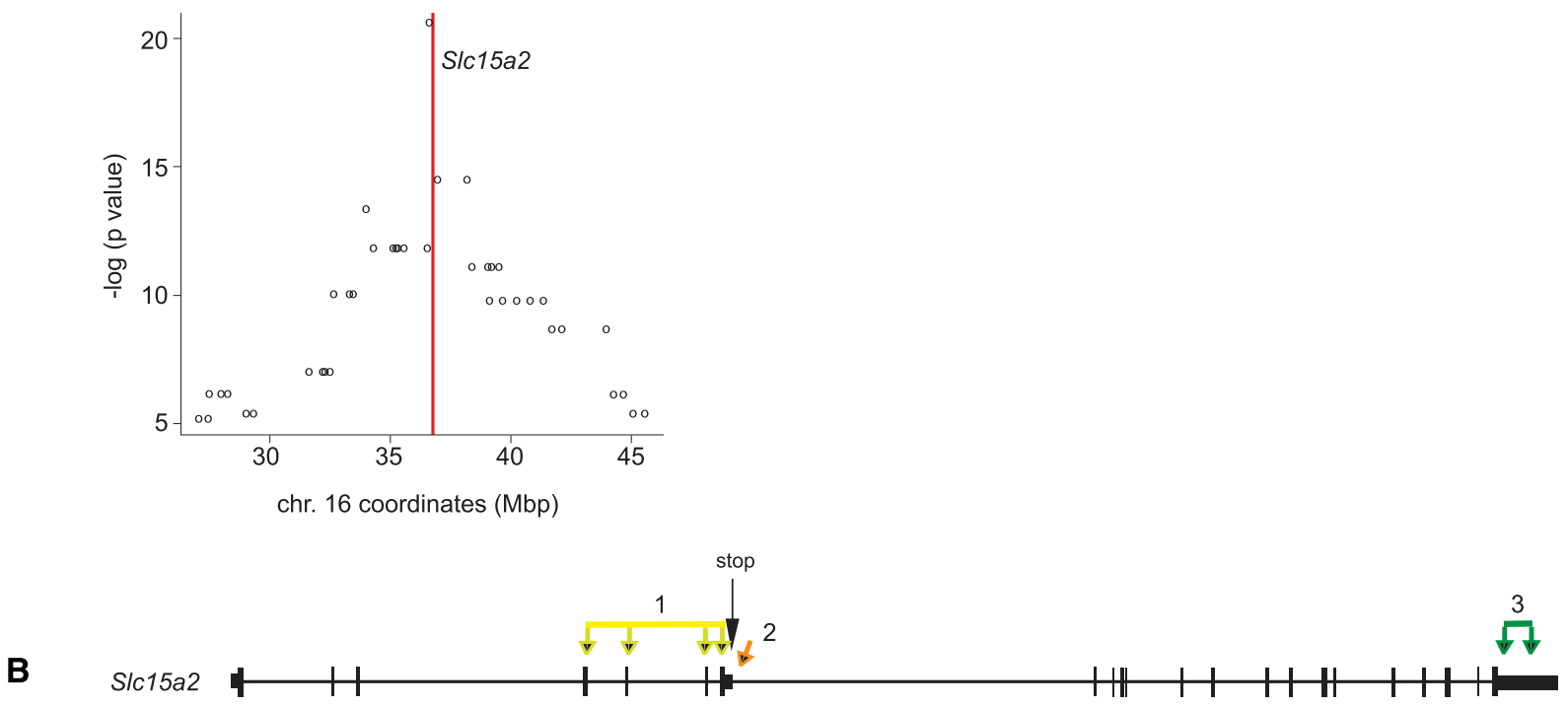

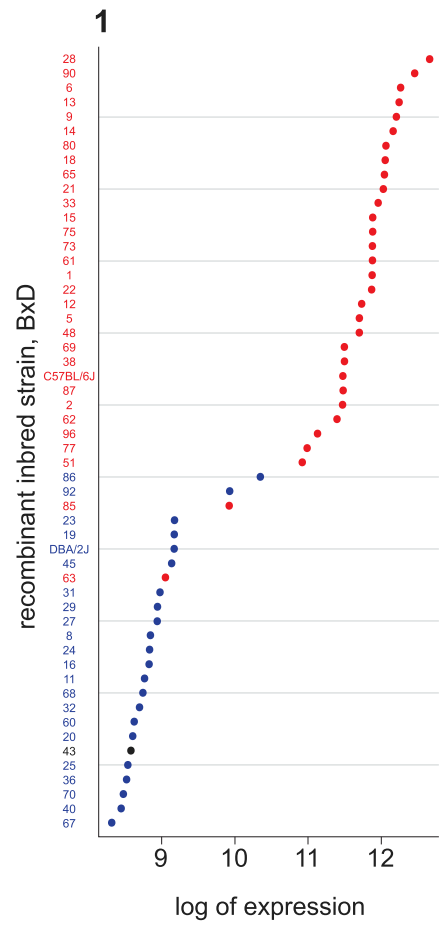

C

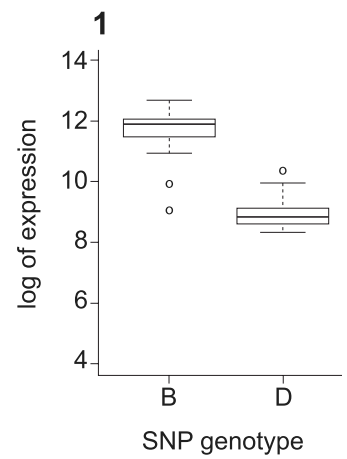

2
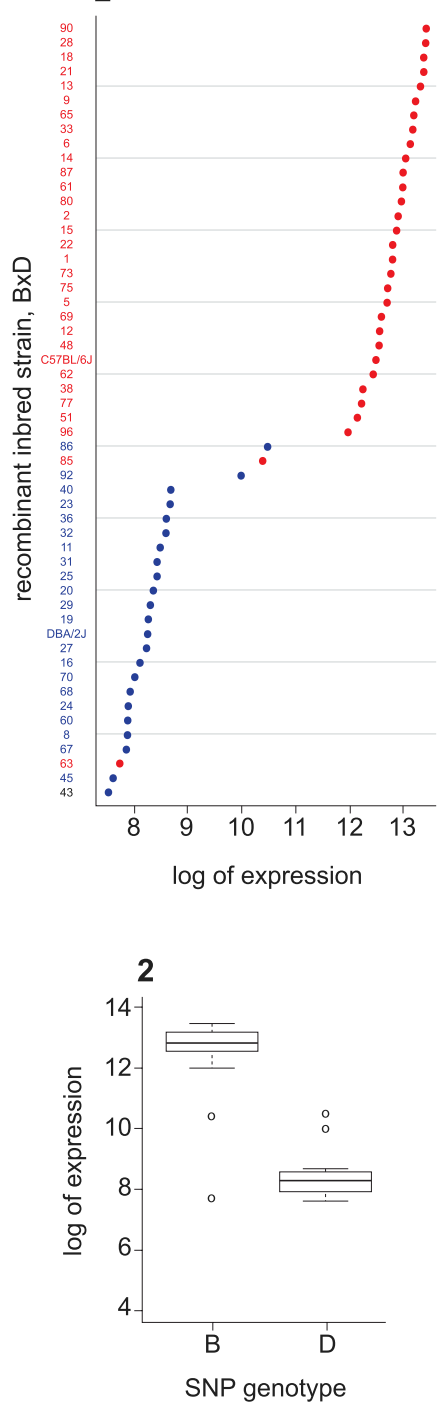

3
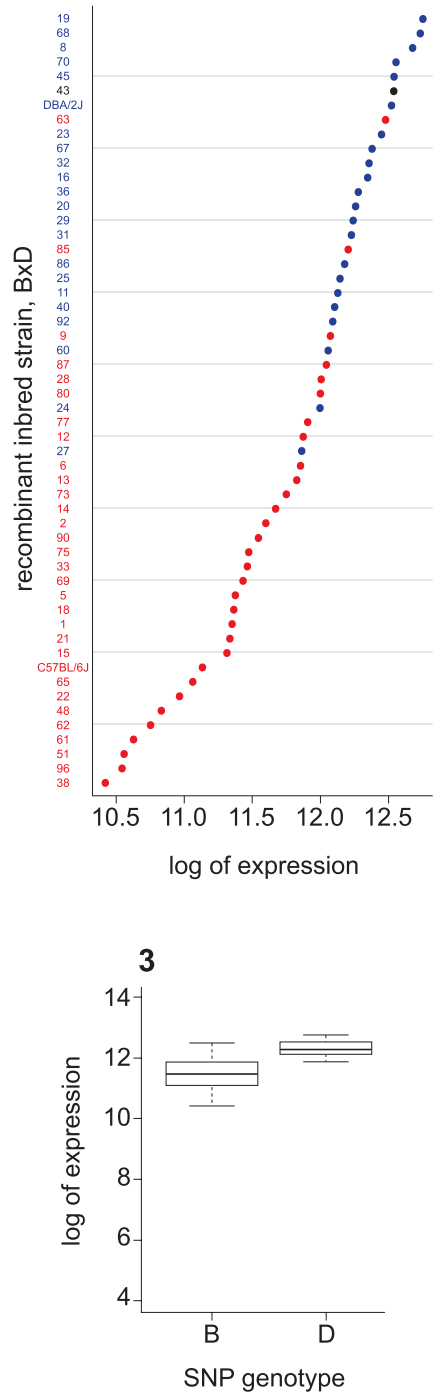

Figure 5. Strong genetic associations between transcriptional disruption and $E_{R V} V_{S I C 15 a 2}$ status in cis. $(A)$ eQTL permutation analysis indicates a very strong association between a SNP (rs4173858) genotype, which serves as a surrogate for ERV SIC1 $152_{2} \sim 137 \mathrm{~kb}$ distant, and expression of the S/c15a2 truncated transcript in mouse recombinant inbred BxD strain kidneys. (Red line) The chromosomal position of S/c15a2; ( $y$-axis) $P$-values were calculated for the association between each SNP at the indicated chromosomal coordinates and truncated S/c15a2 transcript levels. ( $B$, top) Schematic of Affymetrix microarray probe sets detecting $(1,2)$ truncated or $(3)$ full-length transcripts. (Bottom) Individual expression data ( $x$-axis, log scale) measured by microarray probe sets (1-3) for each recombinant inbred BxD strain with indicated SNP genotypes: (red) B6; (blue) DBA; (black) heterozygous or indeterminate. (C) Box plots showing log of transcript expression versus genotypes: (B) B6; (D) DBA/2J. Error bars indicate SD. P-values for expression differences between genotypes $B$ and $D$ were calculated using a $t$-test: probe $1=1.80 \times 10^{-22}$; probe $2=5.53 \times 10^{-23}$, and probe $3=4.58 \times 10^{-10}$. 
A

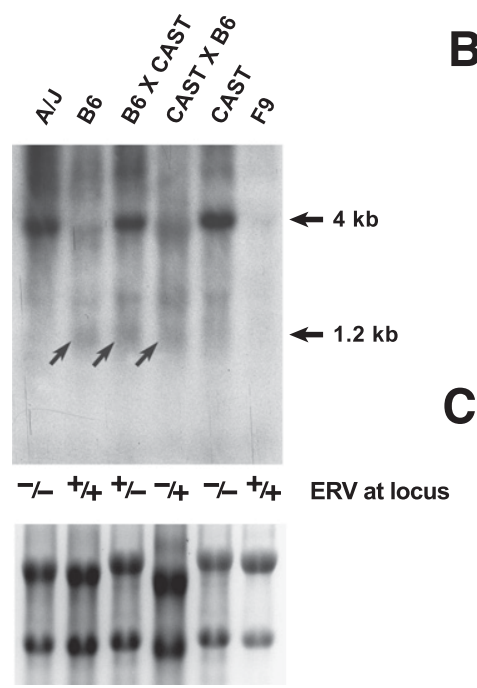

B

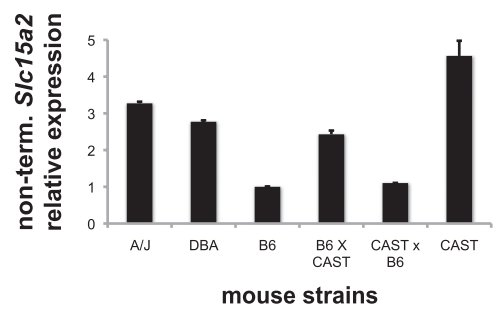

C

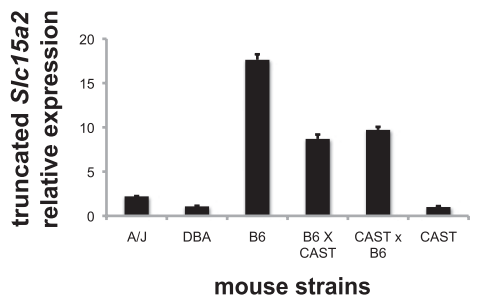

D

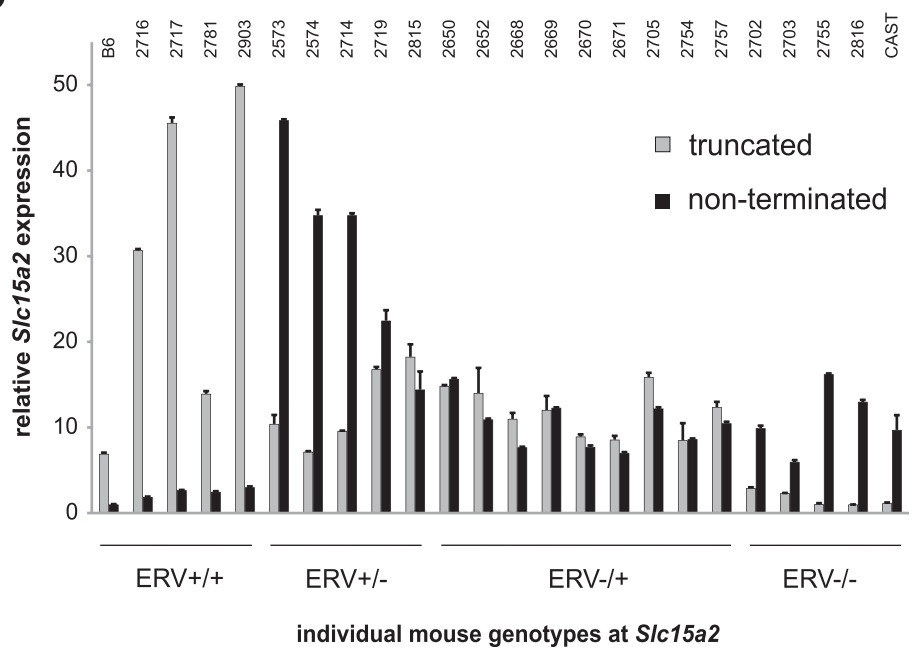

Figure 6. Transcriptional termination occurs between alleles in $\mathrm{F}_{1}$ and $\mathrm{F}_{2}$ mice. $(A$, top) Northern blot demonstrating differential reduction in full-length transcripts in brains from CAST $\times$ B6 but not B6 $\times$ CAST $F_{1}$ hybrid with heterozygous ERV integrants. In contrast, truncated transcripts (arrows) are detected in both lineages. (Bottom) Loading control showing 28S and 18S rRNA. Comparable amounts $(10 \mathrm{mcg})$ of total RNA were loaded in each lane. (B) Quantitative RT-PCR assay for full-length transcripts (extending past exon 7) in brains from various mouse strains. Results are expressed as the fold change in levels relative to the sample with the lowest concentration. (C) Quantitative RT-PCR assay for the $3^{\prime}$ end of prematurely truncated transcripts shows that their expression is boosted specifically in strains containing ERV $\mathrm{SIC15a2.}_{\text {. }}(D)$ Quantitative RT-PCR assays for full-length and prematurely terminated transcripts (each in duplicate or triplicate) in individual mice with indicated genotypes. Results were normalized to Hprt (i.e., hypoxanthine guanine phosphoribosyl transferase) transcript expression. (Error bars) Range of data. Numbers at top are identifiers for individual mice (Supplemental Table 3).

types where the allelic parents of origin are known unambiguously. We quantified both nonterminated and truncated Slc15a2 transcripts in individual whole-brain extracts using qRT-PCR (Fig. 6D; Supplemental Fig. 5; Supplemental Table 4). Consistent with the results presented above (Fig. 3; Supplemental Fig. 3), nonterminated transcripts are significantly reduced in the presence of $\mathrm{ERV}_{\text {Slc15a2, }}$ up to $\sim 16$-fold, compared with its absence. Nonterminated transcript levels also are significantly lower in individuals with the paternally derived $\mathrm{ERV}_{\text {Slc15a2, }}$ compared with its maternal inheritance. Prematurely truncated transcripts are expressed robustly whenever the ERV is present and are increased further when $\mathrm{ERV}_{\text {SIc15a2 }}$ is present in homozygosity, i.e., up to $\sim 49$-fold
(Fig. 6D). The results also demonstrate relatively modest variability between individuals with the same ERV genotype at Slc15a2, regardless of their diverse ancestries. Thus, neither ancestral exposures to the ERV nor unlinked, distant genetic modifiers alter these ERV-mediated effects substantially.

Since the nonterminated transcript levels reflect the parent of origin of the intronic ERV, we were prompted to assess DNA methylation at $\mathrm{ERV}_{\text {SIc15a2 }}$ in various heterozygous and homozygous mice. We observed differential methylation that is associated with the ERV's parent of origin (Fig. 7). Its 5' long terminal repeat (LTR), closer to upstream Slc15a2 exon 7, is relatively hypomethylated in B $6 \times$ CAST F1 mice, with only $\sim 50 \%$ CpGs methylated. The 5' LTR is more densely methylated in B6 $(74 \%)$ and particularly in CAST $\times$ B6 $\mathrm{F}_{1}(91 \%)$ mice. In contrast, the $3^{\prime}$ LTR is densely methylated $(95 \%-100 \%)$ in all lineages tested (Fig. 7). Increased methylation at the 5' LTR is associated with decreased levels of the nontruncated transcripts.

\section{Disruption of other genes by polymorphic, intronic ERVs}

We asked whether intronic ERVs in other, independent genes could disrupt their expression similarly. Using RT-PCR, we identified prematurely truncated transcripts at Polr1a and Spon1 (i.e., spondin 1). The differential expression of truncated transcripts again correlates precisely with the presence or absence of intronic ERVs acting at a distance (Fig. 8; Supplemental Fig. 6; truncated Polr1a transcript, GenBank accession number AK087773.1). The polymorphic ERVs are oriented either parallel or antiparallel, respectively, relative to the genes' reading frames, indicating that transcriptional termination can be triggered independent of the ERV's orientation. While downstream fusion transcripts are robustly expressed in the case of $\mathrm{ERV}_{\text {Polr1a }}$ (data not shown), such expression is not necessary for premature truncation of the overlapping gene (as demonstrated at Slc15a2) (Fig. 3).

Polr1a nonterminated transcripts are significantly reduced with paternally derived $\mathrm{ERV}_{\text {Polr1a }}$ when compared with maternally derived $\mathrm{ERV}_{\text {Polr1a }}$ (Fig. 8D). This is similar to the association between reduced expression of nonterminated (full-length) Slc15a2 and the paternally derived $\mathrm{ERV}_{\text {Slc15a2. Moreover, trun- }}$ cated transcripts are expressed at approximately equivalent levels from both alleles in offspring from both reciprocal crosses (Supplemental Fig. 6). Nonterminated transcripts of Spon1 display biallelic expression, regardless of the parent of origin of $\mathrm{ERV}_{\text {Spon } 1 \text {. }}$ 


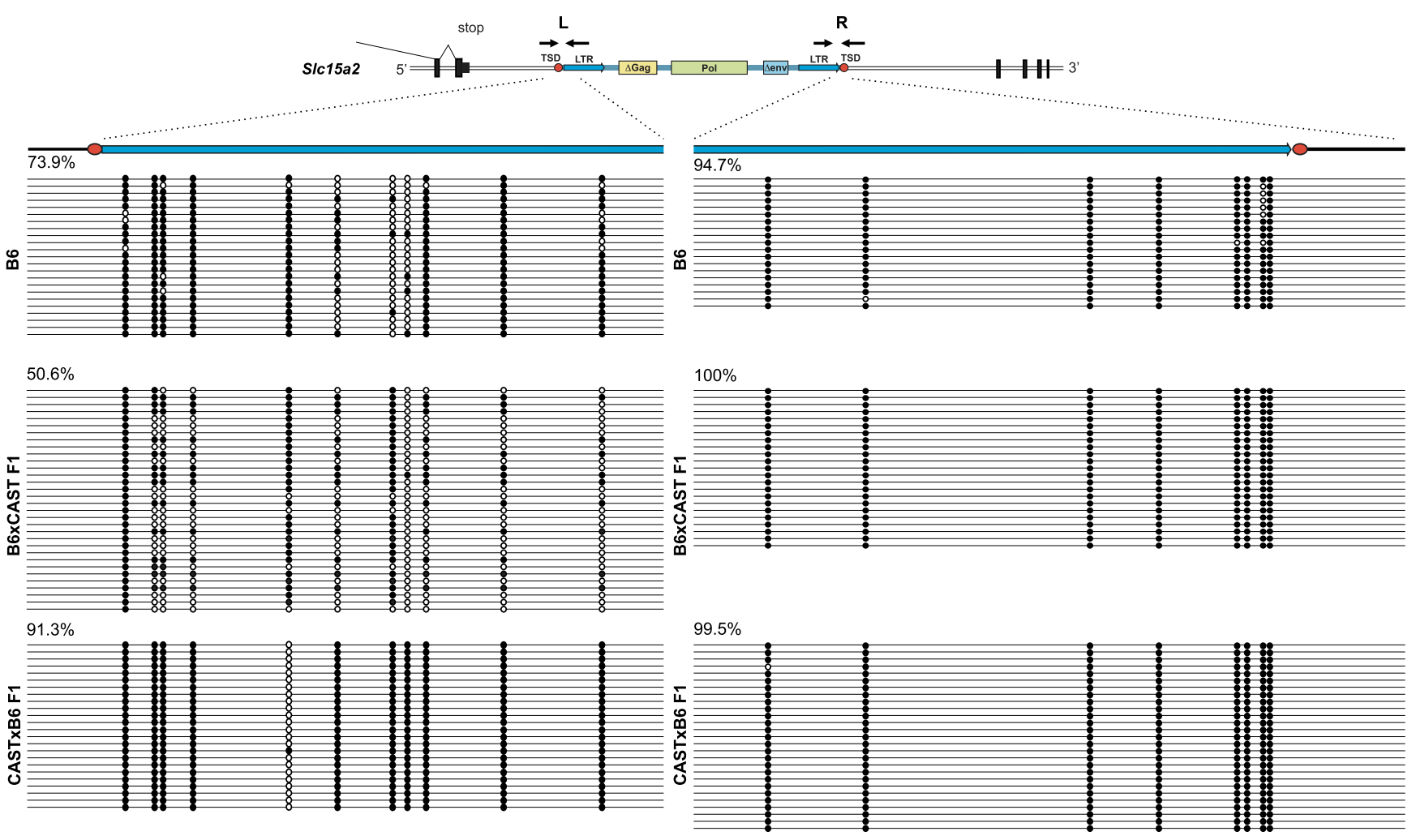

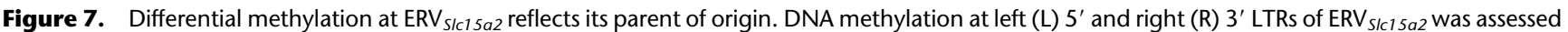
using bisulfite sequencing of genomic DNA purified from brains of indicated mouse lineages. (Top, schematic) In amplicon L, primers DES2652 and DES4883 yielded a 272-nt genomic DNA fragment to assess the methylation status of $11 \mathrm{CpG}$ dinucleotides (circles) presented for multiple cloned alleles (horizontal lines). In amplicon R, primers DES4881 and DES2649 yielded a 304-nt fragment to assess eight CpGs. (Filled circles) Methylated cytosine; (open) unmethylated. (Upper left corner of each panel) Percentages of cytosines that are methylated.

We surveyed the mouse transcriptome for additional candidate genes whose expression may be disrupted by intronic ERVs $<10 \mathrm{~kb}$ away from upstream exons. In addition to reidentifying premature transcriptional termination at Slc15a2, Polr1a, and Cdk5rap1 (i.e., Cabp, CDK5 regulatory subunit associated protein 1) (Druker et al. 2004), this bioinformatics screen identified more than 100 independent genes including non-RefSeq transcripts (Table 2; Supplemental Table 5). Adding the prematurely truncated transcript at Spon1, where full-length transcription is disrupted by an intronic ERV at a genomic distance exceeding $12.5 \mathrm{~kb}$ (Fig. 8), we anticipate that many more prematurely truncated transcripts will be associated with adjacent ERVs in future studies of distinct mouse tissues, developmental stages, and nonreference mouse strains.

\section{Discussion}

By developing the transposon junction assay with targeted deep sequencing, we mapped thousands of young ERVs in highly divergent mouse strains. The resulting catalog of ERV polymorphisms facilitated the identification of particular transcripts whose differential expression in the highly divergent mouse lineages could be attributed to them. Integrants that are identical (i.e., present at orthologous loci) across such widely divergent lineages represent ancestral retrotransposition events that are identical by descent (Salem et al. 2005; Ray et al. 2011), while the youngest integrants are likely to be lineage-specific and are highly polymorphic (Fig. 1;
Zhang et al. 2008; Qin et al. 2010). The ERV polymorphisms occur mostly in extragenic chromosomal regions and are at particularly low densities within embryogenesis genes and genes that are highly expressed in ES cells (Fig. 2). When present, they are oriented mostly antiparallel to the genes' reading frames, extending previous studies to previously unsequenced, highly divergent lineages (Smit 1999; Medstrand et al. 2002; van de Lagemaat et al. 2006; Zhang et al. 2008) and suggesting that they can disrupt gene expression and function. This distribution of polymorphic ERVs also suggests that remaining intronic integrants have survived purifying selection in the diverse mouse lineages over evolutionary time, because older elements are particularly depleted from intragenic sites.

We characterized several genes whose usual expression is disrupted profoundly by polymorphic ERV integrants acting at a distance, both in cis and between alleles. We conclude that the ERVs themselves are the genetic determinants of transcriptional disruption occurring at a distance in cis, because of several observations: (1) There is a strong and consistent association, across many mouse strains, between the presence of high levels of prematurely truncated transcripts and the presence of downstream, polymorphic, intronic ERVs. (2) Multiple independent genes at several different chromosomal positions exhibit similar effects. (3) Expression quantitative trait locus (eQTL) analysis in BxD recombinant strains established very strong genetic associations between the ERV-containing genotype and disrupted transcript isoforms (Fig. 5). (4) There are no other polymorphic genomic

\section{Genome Research} www.genome.org 
$\mathbf{A}$

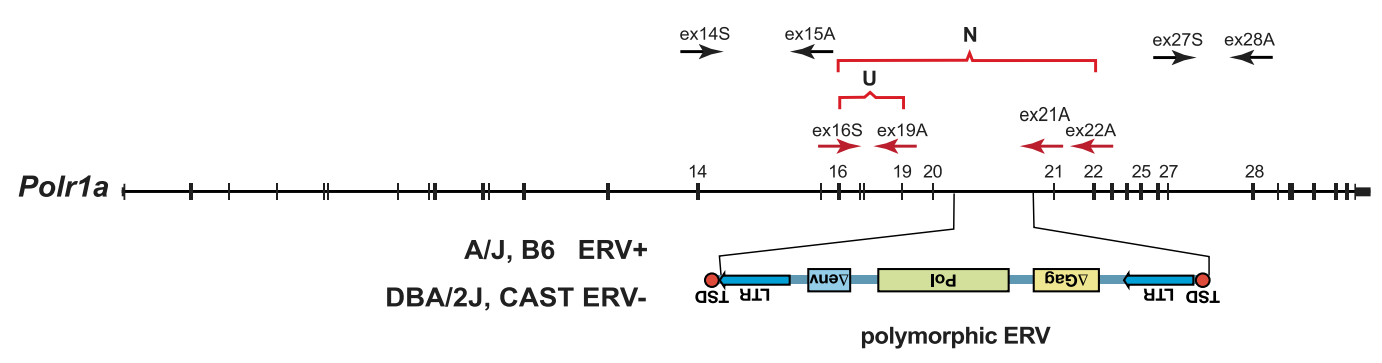

B

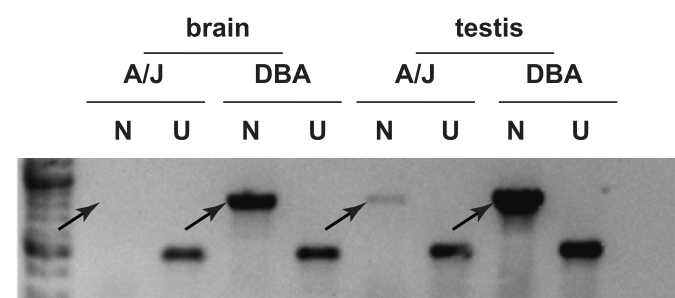

Polr1a

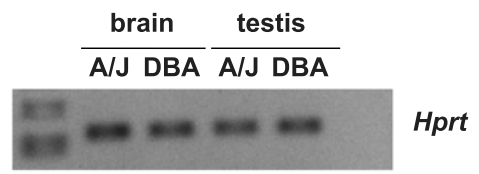

C

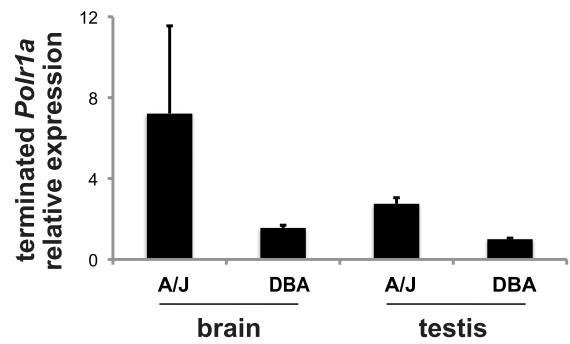

D

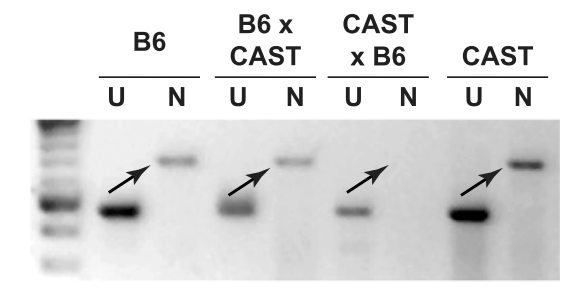

E

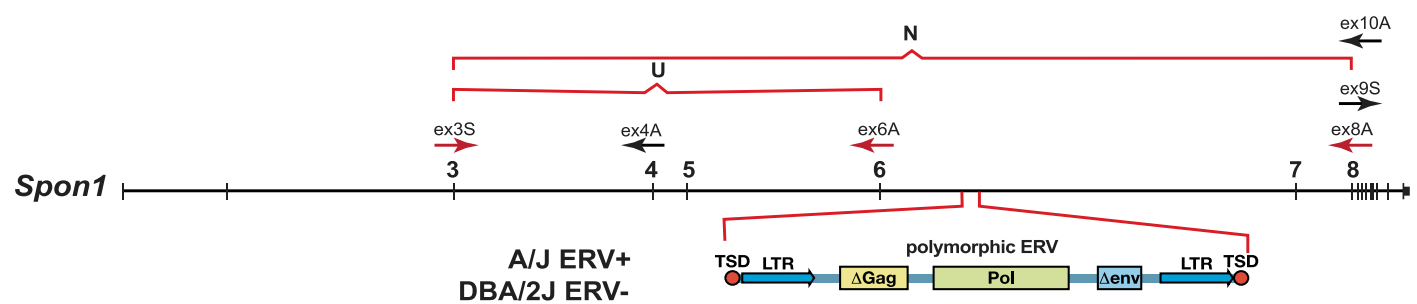

$\mathbf{F}$

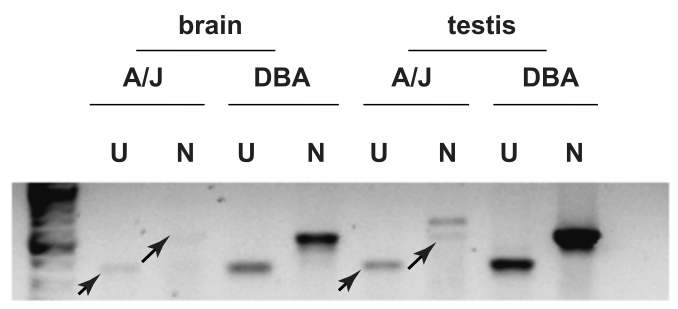

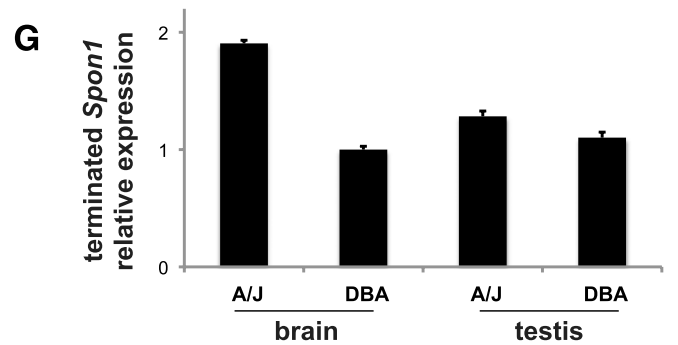

Figure 8. Disruption of additional genes by polymorphic, intronic ERVs in either orientation. (A) Genome structure of Polr 1 a containing a polymorphic AS ERV in intron 20, present in A/J and B6 and absent from DBA/2] and CAST mice. Various PCR primers are shown; (ex) exon number; (S) sense; (A) antisense. (Red arrows and brackets) cDNA amplicons; $(\mathrm{U})$ upstream; $(\mathrm{N})$ nonterminated, i.e., full-length. (B) Premature Polr1 $a$ termination occurs in brain and testis of $\mathrm{A} / \mathrm{J}$ but not DBA mice. RT-PCR assays measured expression of upstream (U) versus nonterminated (N) transcripts, using ex16S and ex19A versus ex16S and ex22A primers, respectively. (Arrows) Differentially expressed, nonterminated transcripts. (Right) Loading control for spliced Hprt transcript assayed by RT-PCR. (C) Quantitative RT-PCR assay measuring relative differences between upstream and downstream Polr1 $a$ transcript levels, i.e., prematurely terminated transcripts. (Error bars) Range of duplicates. $(D)$ Parent-of-origin effect on nonterminated Polr1a transcript levels in heterozygous mice. RT-PCR assays measured expression of upstream $(\mathrm{U})$ vs. nonterminated $(\mathrm{N})$ transcripts, using ex16S and ex19A versus ex16S and ex21A primers, respectively. (Arrows) Differentially expressed, nonterminated transcripts. See Supplemental Figure 6. (E) Genomic structure of Spon1 containing a polymorphic ERV in intron 6, present in A// but not DBA mice. (F) Premature Spon1 termination in brain and testis of A/J but not DBA mice. (Arrows) Differentially expressed, upstream $(\mathrm{U})$ and nonterminated $(\mathrm{N})$ transcripts shown by RT-PCR assays. Both upstream and particularly full-length Spon 1 transcripts are reduced in A/J mice (based on similar input RNA levels vs. DBA mice). (G) Quantitative RT-PCR assay measuring relative differences between upstream and downstream Spon1 transcript levels, i.e., prematurely terminated transcripts. (Error bars) Range of duplicates. 
Table 2. Identification of candidate transcripts truncated prematurely by ERV integrants

\begin{tabular}{|c|c|c|}
\hline \multicolumn{3}{|l|}{ Gene name } \\
\hline 1200014J11Rik & Dtd1 & Phf8 \\
\hline $2010015 L 04 R i k$ & Dym & Pkd1/2 \\
\hline 2010111101 Rik & E130309F12Rik & Polr1a \\
\hline 2510009E07Rik & Enpp6 & Poteg \\
\hline $3300002108 R i k$ & Epb4.1/2 & Prrxl1 \\
\hline 4930430F08Rik & Eps15 & Qrs/1 \\
\hline 6720457D02Rik & Exoc6 & Rab3gap1 \\
\hline Abcg 3 & Fancd2 & Ralgapa1 \\
\hline Acly & Galk2 & Rhbdl2 \\
\hline Adamts 3 & Galnt10 & Rnf157 \\
\hline Agbl4 & Gimap5 & Sag \\
\hline Akr1c14 & Gm4979 & Sema3d \\
\hline Angpt1 & Golga3 & Sgip1 \\
\hline Arfgef2 & Gpsm1 & Sirt5 \\
\hline$A s b 3$ & lars2 & Slc15a2 \\
\hline Atp6v1h & Ifi44 & SIc17a5 \\
\hline$B m x$ & lqca & S/c20a2 \\
\hline Ccdc15 & Irak3 & SIc25a46 \\
\hline Ccdc46 & $\operatorname{ltg} b 3 b p$ & S/c38a1 \\
\hline Cdk5rap1 & Katnal1 & Slco6b1 \\
\hline Cenpq & Klhl13 & $\operatorname{Sn} \times 29$ \\
\hline Chl1 & Lama3 & Sypl2 \\
\hline Cmah & Letm1 & $T b c 1 d 22 a$ \\
\hline $\operatorname{Cog} 6$ & Mapk4 & Tcfcp2 \\
\hline Col4a4 & $\mathrm{Me} 3$ & Tmco3 \\
\hline Ctps2 & Me3 & Tmed7 \\
\hline Сур20а1 & Mllt10 & Trpm2 \\
\hline Dcp1b & Myom1 & Txndc1 1 \\
\hline Dctn4 & Ophn1 & Uty \\
\hline Diap3 & Orai2 & Vps52 \\
\hline Dnahc1 & Otoa & Whsc1 \\
\hline Dnahc7b & Paqr3 & Zfand3 \\
\hline Dph5 & Parp4 & Zfp407 \\
\hline Dsg2 & Phc3 & \\
\hline
\end{tabular}

Listed here are candidate genes that may be disrupted by ERV (IAP) integrants found within $10 \mathrm{~kb}$ genomic distance downstream from premature termination sites. This analysis focused on reference B6 genes because currently available mouse transcriptome data are limited mostly to this strain. Slc15a2 (Figs. 3-7), Polr1a (Fig. 8), and Cdk5rap1 (Druker et al. 2004) were identified in this screen. Spon1 is not listed here, although its transcription is disrupted by an intronic ERV (Fig. 8), because we limited this screen to identify only candidate ERVs $<10 \mathrm{~kb}$ from the premature termination site.

features in cis that plausibly or consistently explain the observed expression differences.

The prematurely terminated transcripts identified here read past canonical splice donor sites and appear to use pre-existing intronic polyadenylation signal sequences that otherwise are not used routinely (Fig. 4B). We hypothesize that the polymorphic ERVs dramatically alter the use of these splicing and termination signals, which are nonpolymorphic regardless of the integrants' presence or absence (Figs. 3B, 4A). Such alternative transcriptional processing can occur coordinately (Wang et al. 2008), as exemplified by lamins expressed from Lmnb2 (Furukawa and Hotta 1993) and LMNA (Lin and Worman 1993). Resulting transcripts containing intronic sequences at their 3 ' ends have been termed "composite exons" (Yan and Marr 2005).

Similar transcriptional termination occurring at a distance has been attributed to an intronic ERV in Cdk5rap1 (Druker et al. 2004). To our knowledge, the prematurely truncated Cdk5rap1 transcripts are the only previously reported case of transcriptional disruption occurring upstream of such an ERV integrant. However, significant variability in levels of both downstream and pre- maturely terminated upstream $C d k 5$ rap 1 transcripts was described between individual animals. Thus, the Cdk5rap1 locus was described as a "metastable epiallele," comparable to highly variable expression of $A^{v y}$ and $A x i n 1^{F u}$ (Morgan et al. 1999; Whitelaw and Martin 2001). In contrast, we did not observe such a high degree of inter-individual variability at Slc15a2 (Figs. 3, 6; Supplemental Fig. 5).

Nonterminated (i.e., full-length) transcript levels at Slc15a2 and Polr1a reflect the parent of origin of heterozygous ERVs (Figs. 6, 8; Supplemental Figs. 3, 5, 6). When the intronic, heterozygous ERV was derived from the father, expression of nonterminated transcripts is reduced significantly from both alleles. In contrast, when the heterozygous ERV was maternally derived, full-length transcripts are expressed robustly, i.e., at levels similar to those in the ERV's absence. Regardless of the ERV's parent of origin and their overall expression, the nonterminated transcripts are expressed from both allelic templates at approximately equivalent levels (Supplemental Figs. 3, 6). Previously, transposons have been implicated as targets for establishment of imprinting and differentially methylated regions at particular loci (Suzuki et al. 2007), although a detailed molecular mechanism was not described. We found that the 5' LTR of heterozygous ERV SIc15a2 is differentially methylated, depending on its parent of origin (Fig. 7). When inherited from the father, the 5' LTR is densely methylated, whereas when it is maternally inherited its methylation is reduced. This differential epigenetic control appears to be associated with differential levels of nonterminated transcripts. Such silencing epigenetic marks may mediate this parent-of-origin effect possibly by affecting transcriptional processivity past the ERV (Rebollo et al. 2011), although this does not directly explain the effects between alleles that we observed. The ERV's 3' LTR is consistently methylated, regardless of its parent of origin (Fig. 7).

We did not observe a parent-of-origin effect in expression levels of prematurely truncated transcripts. Their expression appears to be boosted whenever the ERV is present. Moreover, the expression of full-length and truncated transcripts is not always inversely correlated; they do not sum up to a constant level of upstream initiation and transcription (Fig. 6D; Supplemental Fig. 5). This implies that transcriptional initiation, prolongation, splicing, and premature termination may not be coordinately regulated in some cases, and instead may undergo independent, complex patterns of regulation.

Several other distinct cases of transcriptional regulation and disruption illustrate multiple potential effects by ERVs on gene expression. An inverse association was reported between differential DNA methylation of the Cdk5rap1 intronic ERV's 5' LTR and premature termination of $C d k 5$ rap 1 transcripts (Druker et al. 2004). Additionally, nonterminated Cdk5rap 1 transcripts are consistently expressed, independent of the terminated transcripts' variable expressivity. In axin fused mice, variable expression of downstream Axin transcripts has been associated with differential methylation of the 5' LTR of the intronic ERV in the $A x^{F u}$ allele, and either parent can transmit the epigenetic state (Rakyan et al. 2003). In contrast, in the $A^{v y}$ mouse, variable expressivity of nonagouti is related to differential methylation of the $5^{\prime}$ LTR of an upstream ERV, and the epigenetic state is maternally inherited (Morgan et al. 1999). Transcripts from the imprinted mouse gene $H 13$ recently were found to undergo alternative polyadenylation that is regulated epigenetically by differential methylation of an internal promoter, albeit not in an ERV (Wood et al. 2008). Thus these various distinct expression patterns contrast with the transcriptional disruption described here. 
Recently, bioinformatics analysis of the human transcriptome correlated antisense (AS) transcription with alternative splicing of overlapping sense-strand transcripts (Morrissy et al. 2011). The aberrantly spliced and terminated transcripts at Cdk5rap1 (Druker et al. 2004) were attributed tentatively to possible AS transcription initiated from the intronic ERV promoter. However, evidence for AS transcription was not demonstrated, and the underlying molecular mechanism remains unknown. Such a model for transcriptional interference, i.e., collisions of bidirectional RNA polymerase complexes (Eszterhas et al. 2002), plausibly could explain Cdk5rap1 disruption (Druker et al. 2004). However, transcriptional interference would not explain transcript expression differences between alleles as described here (Figs. 6, 8; Supplemental Figs. 3, 5, and 6). Alternatively, diffusible AS transcripts could act at long genomic distances, both in cis and between alleles. AS transcripts could affect host gene splicing by blocking U1 snRNA base-pairing with pre-mRNAs (Kaida et al. 2010). ERV-mediated alterations in gene "punctuation," where the polymorphic ERV could alter gene looping or interactions between homologous alleles by disrupting long-range interactions between upstream gene promoters and various downstream terminator sites (Tan-Wong et al. 2008), could provide another explanation for transcriptional disruption. Intragenic ERV integrants could introduce targets for heterochromatin formation that could disrupt full-length transcription in cis. Other possibilities also are plausible (Wilusz and Spector 2010).

We identified about 100 intronic ERV candidates that may trigger premature transcriptional termination at a distance (Table 2), out of approximately 1025 genes displaying evidence for premature termination. We speculate that other types of ERVs (i.e., ETn/ MusD elements) (Zhang et al. 2008), retrotransposons, or repetitive elements similarly could trigger transcriptional truncation in at least some of the remaining $\sim 90 \%$ of genes lacking such intronic ERV candidates. We are addressing this interesting question currently.

Extrapolating from the number of intronic ERV polymorphisms identified in diverse mouse lineages, we estimate that up to $\sim 10 \%$ of all genes containing intronic ERVs exhibit transcriptional disruption mediated by the integrants acting at a distance. This calculation may underestimate the full extent of ERVmediated transcriptional disruption, since comprehensive transcipt expression data are lacking from various tissues and developmental time points from the divergent strains studied here. On the other hand, most of these candidates have not been validated by molecular assays. We did not detect a significant difference in the relative orientation of intronic ERVs that appear to trigger premature truncation (i.e., $\sim 30 \%$ AS compared with overlapping genes), when compared with all intronic ERVs (i.e., $\sim 23 \%$ AS, $p=0.102$ ). We postulate that thousands of other intronic ERVs present in different lineages (Table 1) are unlikely to disrupt overlapping gene expression and function in this way, because such genes presumably lack the pre-existing, weak polyadenylation or alternative splicing signals that could be boosted by them. De novo intronic ERV integrants that strongly affect gene transcription, particularly of essential genes, would be expected to be highly deleterious, explaining their relative exclusion from embryogenesis genes and genes highly expressed in ES cells (Fig. 2). This conclusion is consistent with the demonstration that fusion transcripts are initiated from ERV LTR promoters in oocytes and in early embryogenesis (Peaston et al. 2004).

Our results strongly suggest that genome-wide studies based solely on SNP genotyping may miss important determinants of transcriptional variation and functional diversity. Comprehensive knowledge of all forms of structural variation within and between individuals, including indel polymorphisms caused by actively mobilized repetitive elements such as ERVs, will be critically important to understand the molecular basis for phenotypic variation (Li et al. 2010; Keane et al. 2011; Yalcin et al. 2011). Although ERVs appear to be inactive in humans, $\sim 10 \%$ of the genome is comprised of such elements, suggesting that similar transcriptional disruption could be mediated by their promoter activities. While too numerous and diverse to describe here, other transposon families and retroposed elements continue to be actively mobilized in both the mouse and human genomes, thereby also introducing promoter activities, new polyadenylation signal sequences in cis (Li et al. 2010), new splicing sites, and targets for epigenetic regulation (Macfarlan et al. 2011; Monk et al. 2011). Further characterization of the molecular causes and consequences of transcriptional variation caused by genomic ERVs and other families of transposons and, in particular, the detailed mechanisms for premature transcriptional polyadenylation triggered at a distance undoubtedly will be promising areas for further study.

\section{Methods}

\section{Mouse colony and genomic DNA}

Mice were maintained and euthanized according to approved Institutional Animal Care and Use Committee protocols (National Cancer Institute, Frederick, MD; and Ohio State University, Columbus, $\mathrm{OH})$. Mouse strains and purified genomic DNA were purchased from the Jackson Laboratory (Bar Harbor, ME).

\section{Bioinformatics tools and statistical analysis}

Alignments of pyrosequencing reads to the B6 reference genome assembly were performed using GMAP (Wu and Watanabe 2005; Akagi et al. 2008), BLAT, and BLAST. Results were parsed using custom Perl scripts with BioPerl modules. Statistical analyses were performed using SPSS (http://www.spss.com) or R software as described. Analysis of mouse ES cell expression data was based on public data sets in the GEO repository under accession number GSE8024 (Mikkelsen et al. 2007). Genes annotated as embryogenesis genes were identified from the Mouse Genome Informatics database (http://www.informatics.jax.org).

Further details about our assessment of possible bias in detecting ERVs using the transposon junction assay and our procedures for identification of ERVs in four "Celera strains" are provided in the Supplemental Material. To assess their chromosomal distributions (Supplemental Fig. 2), we counted retrotransposons in $500-\mathrm{kb}$ bins genome-wide. Reference distributions of retrotransposons for each class (L1, ERV, and SINE) were obtained from the UCSC mm8 mouse reference assembly. Similarly, polymorphic retrotransposon distributions were determined by counting both unique insertions in reference and insertions in alternative strains we identified from four strains by Celera shotgun sequencing (Mural et al. 2002).

To identify candidate genes with prematurely truncated transcripts (Table 2), we compared chromosomal coordinates of $\sim 20,180$ RefSeq reference genes (UCSC Genome Browser) with those from the Known Gene track in the UCSC database. We compared annotated gene symbols in cases in which the genomic template for a Known Gene transcript is $>20 \mathrm{~kb}$ shorter than that for a corresponding RefSeq gene transcript. In approximately 1025 cases in which the assigned NCBI gene ID numbers are 
identical, we called such a Known Gene transcript a truncated variant of the full-length RefSeq gene. In such cases, we scanned within $10 \mathrm{~kb}$ downstream from the $3^{\prime}$ end of the truncated transcript for ERV elements (i.e., all IAP subtypes as defined by RepeatMasker).

\section{Identification of ERVs using transposon junction assay}

To map previously unsequenced ERV integrants in divergent mouse lineages, we developed a new high-throughput assay using nested PCR (Pornthanakasem and Mutirangura 2004) to amplify genomic sequences containing $3^{\prime}$ junctions of transposon integrants, followed by deep 454 sequencing (Supplemental Fig. 1). Forward PCR primers were designed to anneal within young, highly conserved ERV integrant sequences; details are provided in the Supplemental Material. Resulting sequence traces were aligned to the $\mathrm{mm} 8$ mouse reference genome and analyzed for indel polymorphism status, using modifications of our sequence alignment pipeline described in the Supplemental Material (Akagi et al. 2008). To identify previously unsequenced ERV integrants, sequencing reads from these PCR amplicons were mapped to the reference mouse genome assembly in three steps: preprocessing of reads, mapping of reads, and clustering of overlapping reads defining discrete insertion sites. We used this assay to identify previously unsequenced ERV elements in six diverse mouse lineages, i.e., A/J, B6, CAST, MOLF, SPRET, and WSB.

\section{RNA isolation}

To preserve high-quality total RNAs for downstream transcriptome analysis, we collected tissues from both sexes of inbred mouse strains at day 72. RNAs were collected from strains B6, 129S1, 129X1, DBA/2J, A/J, CAST, SPRET, MOLF, WSB, and intercrossed $\mathrm{F}_{1}$ hybrid offspring $\mathrm{B} 6 \times \mathrm{CAST}$, and CAST $\times \mathrm{B} 6$, respectively. Trimmed tissues were immediately immersed in RNA Later (Ambion) and either snap-frozen at $-80^{\circ} \mathrm{C}$ or transferred to TRIzol (Invitrogen), homogenized, and frozen. The quality of total RNAs was determined using a model 2100 Agilent bioanalyzer where $>95 \%$ of the samples had RIN scores $>9$. RNA specimens isolated from the same strain, tissue, gender, etc. were pooled from at least five individuals, unless noted.

\section{Northern blots and RT-PCR assays}

Total RNAs from indicated mouse tissues were electrophoresed in agarose gels under standard conditions, transferred to charged nylon membranes (GE Amersham), and hybridized with radiolabeled DNA probes at the 5' and 3' ends, respectively, of Slc15a2 transcripts. Membranes were washed and exposed to film for autoradiography. To synthesize first-strand cDNAs for reverse transcriptase-mediated polymerase chain reaction (RT-PCR) assays, 10 $\mu \mathrm{g}$ each of mouse total RNAs was primed for reverse transcription, using T7-anchored oligo(dT) $)_{24}$ and SuperScript II Reverse Transcriptase (Invitrogen). Gene-specific primers for Slc15a2, Polr1a, and Spon1 were used to amplify resulting first-strand cDNAs. Products were assessed by agarose gel electrophoresis. Quantitative RT-PCR was performed using these cDNAs and Power SYBR Green PCR master mix (ABI) on a StepOnePlus instrument (ABI). To quantify relative expression of Polr1a truncated transcripts (Fig. 8), we measured upstream and downstream transcript levels, calculated the difference in PCR cycle numbers $\Delta \Delta \mathrm{C}_{\mathrm{T}}=(\mathrm{ex} 14 \mathrm{~S}-\mathrm{ex} 15 \mathrm{~A})-$ (ex27S-ex28A), and then calculated linear differences as $2^{\Delta \Delta \mathrm{C}_{\mathrm{T}}}$. Spon1 premature truncation was measured similarly. Further details are in the Supplemental Material.

\section{RACE}

5 '- and 3'-RACE analyses were performed using the 5/3 RACE Kit, second generation (Roche Applied Science), the FirstChoice RLMRACE kit (Ambion), and primers for Slc15a2 (DES2622, 5'-CTTC TGACAAGCACTCTGGAG-3') and Polr1a (DES4410, 5'-TGGTCT CACCCTTTCTGTAACG-3') according to the kit manufacturers' protocols.

\section{Western blots and PEPT2 functional assay}

PEPT2 protein expression in tissues from individual mice was assayed by Western blots as described in the Supplemental Material. To assay PEPT2 protein functional activity, six B6 mice (three females, three males) and five DBA/2J mice (three females, two males) were injected via tail vein injection with $100 \mu \mathrm{L}$ of GlySar solution containing $5 \mu \mathrm{Ci}$ of ${ }^{14} \mathrm{C}-\mathrm{GlySar}(98 \mathrm{mCi} / \mathrm{mmol}, 0.1 \mathrm{mCi} / \mathrm{mL}$; Moravek). Tissue concentrations of GlySar (nanomoles per gram of wet tissue) were calculated as described in the Supplemental Material (Ocheltree et al. 2005; Shen et al. 2007).

\section{Expression quantitative trait locus analysis}

Slc15a2 expression data from kidneys of $53 \mathrm{BxD}$ RI mouse strains were obtained from the Gene Network (http://www.genenetwork.org). Transcript levels were measured using the Affymetrix M430v2 platform (database access code MA_M2_0806_R), which includes three Slc15a2-specific probe sets. Two of these probe sets detect the $3^{\prime}$ end of truncated transcripts (1424730_a_at, 1447808_s_at), and the other detects the $3^{\prime}$ end of the full-length transcript (14171600_at) (Fig. 5B). To assess local strain genotypes B (B6) and D (DBA), 72 informative SNPs within $10 \mathrm{Mb}$ on either side of Slc15a2 were identified from the Gene Network. Expression levels for each genotype $\mathrm{B}$ and $\mathrm{D}$ were determined, and $P$-values were calculated using a $t$-test with multiple test correction according to the Holm method. For all three Slc15a2 probe sets, the maximal $-\log (P$-value $)$ occurred at the SNP rs4173858, the closest informative SNP to Slc15a2 in cis. Additional genomic sequence variants including SNPs and small indel polymorphisms flanking Slc15a2 were identified in B6 and DBA/2J strains using Sanger Institute mouse genome sequencing data (http://www.sanger.ac.uk/ resources/mouse/genomes/; SNP 20110125 release REL1101 and indel20100713 release REL1007).

\section{Data access}

Sequences as indicated were assigned Genbank accession numbers JF495121-JF495122. All ERVs identified here are accessible via our MouseIndelDB website at http://variation.osu.edu/ (Akagi et al. 2010).

\section{Acknowledgments}

We thank Drs. Albert de la Chapelle, Neal Copeland, and Maura Gillison for helpful comments; Robert Williams, Lu Lu, and Jesse F. Ingels (University of Tennessee) for help with the Gene Network and providing several BxD RI mouse strain genomic DNA samples; Holly Morris, Rob Koogle, and Sherry Rausch (National Cancer Institute) for superb maintenance of our mouse colony; Xiaolin $\mathrm{Wu}$ and Hongling Liao (SAIC Frederick) for assistance with exon microarray experiments; Clive Evans (Virginia Bioinformatics Institute) for 454 sequencing; and Richard Frederickson (SAIC Frederick) and Anthony Baker (OSU) for graphical illustration. This project was supported by the Intramural Research Program, Center for Cancer Research, National Cancer Institute, National Institutes

\section{Genome Research}


of Health (to J.L., K.A., A.L.T., D.A.S., T.C.M., D.E.Sy.); NIH research grant R01-GM035498 (to Y.H. and D.E.Sm.); contract no. HHSN261200800001E by the National Cancer Institute to SAIC, Inc. (to N.V., T.C.M., Y.G., and R.M.S.); and by The Ohio State University Comprehensive Cancer Center (to J.L., K.A., C.J.W.H., and D.E.Sy.). We thank the Ohio Supercomputer Center for providing computational resources (grant PAS0425-2 to K.A. and D.E.Sy.). The content of this publication does not necessarily reflect the views or policies of the Department of Health and Human Services, nor does mention of trade names, commercial products, or organizations imply endorsement by the U.S. Government. NCI-Frederick and OSU are accredited by the Association for Assessment and Accreditation of Laboratory Animal Care International and follow the U.S. Public Health Service Policy for the Care and Use of Laboratory Animals. Animal care was provided in accordance with the procedures outlined in the "Guide for Care and Use of Laboratory Animals" (National Research Council, 1996, National Academy Press, Washington, DC). Mouse studies were performed following protocols approved by the Animal Care and Use Committee, NCI Frederick or by the Institutional Animal Care and Use Committee, OSU.

\section{References}

Adams DJ, Dermitzakis ET, Cox T, Smith J, Davies R, Banerjee R, Bonfield J, Mullikin JC, Chung YJ, Rogers J, et al. 2005. Complex haplotypes, copy number polymorphisms and coding variation in two recently divergent mouse strains. Nat Genet 37: 532-536.

Akagi K, Li J, Stephens RM, Volfovsky N, Symer DE. 2008. Extensive variation between inbred mouse strains due to endogenous L1 retrotransposition. Genome Res 18: 869-880.

Akagi K, Stephens RM, Li J, Evdokimov E, Kuehn MR, Volfovsky N, Symer DE. 2010. MouseIndelDB: A database integrating genomic indel polymorphisms that distinguish mouse strains. Nucleic Acids Res 38: D600-D606.

Banno F, Kaminaka K, Soejima K, Kokame K, Miyata T. 2004. Identification of strain-specific variants of mouse Adamts 13 gene encoding von Willebrand factor-cleaving protease. J Biol Chem 279: 30896-30903.

Barr SD, Leipzig J, Shinn P, Ecker JR, Bushman FD. 2005. Integration targeting by avian sarcoma-leukosis virus and human immunodeficiency virus in the chicken genome. J Virol 79: 12035-12044.

Beaudoing E, Gautheret D. 2001. Identification of alternate polyadenylation sites and analysis of their tissue distribution using EST data. Genome Res 11: $1520-1526$.

Brady T, Lee YN, Ronen K, Malani N, Berry CC, Bieniasz PD, Bushman FD. 2009. Integration target site selection by a resurrected human endogenous retrovirus. Genes Dev 23: 633-642.

Brandsch M, Knutter I, Bosse-Doenecke E. 2008. Pharmaceutical and pharmacological importance of peptide transporters. J Pharm Pharmacol 60: $543-585$

Cachon-Gonzalez MB, San-Jose I, Cano A, Vega JA, Garcia N, Freeman T, Schimmang T, Stoye JP. 1999. The hairless gene of the mouse: Relationship of phenotypic effects with expression profile and genotype. Dev Dyn 216: 113-126.

Cahan P, Li Y, Izumi M, Graubert TA. 2009. The impact of copy number variation on local gene expression in mouse hematopoietic stem and progenitor cells. Nat Genet 41: 430-437.

Chesler EJ, Lu L, Shou S, Qu Y, Gu J, Wang J, Hsu HC, Mountz JD, Baldwin $\mathrm{NE}$, Langston MA, et al. 2005. Complex trait analysis of gene expression uncovers polygenic and pleiotropic networks that modulate nervous system function. Nat Genet 37: 233-242.

Copeland NG, Hutchison KW, Jenkins NA. 1983. Excision of the DBA ecotropic provirus in dilute coat-color revertants of mice occurs by homologous recombination involving the viral LTRs. Cell 33: 379-387.

Dewannieux M, Dupressoir A, Harper F, Pierron G, Heidmann T. 2004. Identification of autonomous IAP LTR retrotransposons mobile in mammalian cells. Nat Genet 36: $534-539$.

Druker R, Bruxner TJ, Lehrbach NJ, Whitelaw E. 2004. Complex patterns of transcription at the insertion site of a retrotransposon in the mouse. Nucleic Acids Res 32: 5800-5808,

Eszterhas SK, Bouhassira EE, Martin DI, Fiering S. 2002. Transcriptional interference by independently regulated genes occurs in any relative arrangement of the genes and is influenced by chromosomal integration position. Mol Cell Biol 22: 469-479.
Furukawa K, Hotta Y. 1993. cDNA cloning of a germ cell specific lamin B3 from mouse spermatocytes and analysis of its function by ectopic expression in somatic cells. EMBO J 12: 97-106.

Horie K, Saito ES, Keng VW, Ikeda R, Ishihara H, Takeda J. 2007. Retrotransposons influence the mouse transcriptome: implication for the divergence of genetic traits. Genetics 176: 815-827.

Howard G, Eiges R, Gaudet F, Jaenisch R, Eden A. 2007. Activation and transposition of endogenous retroviral elements in hypomethylation induced tumors in mice. Oncogene 27: 404-408.

Hu Y, Shen H, Keep RF, Smith DE. 2007. Peptide transporter 2 (PEPT2) expression in brain protects against 5 -aminolevulinic acid neurotoxicity. J Neurochem 103: 2058-2065.

Iskow RC, McCabe MT, Mills RE, Torene S, Pittard WS, Neuwald AF, Van Meir EG, Vertino PM, Devine SE. 2010. Natural mutagenesis of human genomes by endogenous retrotransposons. Cell 141: 1253-1261.

Jiang H, Hu Y, Keep RF, Smith DE. 2009. Enhanced antinociceptive response to intracerebroventricular kyotorphin in Pept2 null mice. J Neurochem 109: 1536-1543

Kaida D, Berg MG, Younis I, Kasim M, Singh LN, Wan L, Dreyfuss G. 2010. U1 snRNP protects pre-mRNAs from premature cleavage and polyadenylation. Nature 468: 664-668.

Kapitonov VV, Jurka J. 2008. A universal classification of eukaryotic transposable elements implemented in Repbase. Nat Rev Genet 9: 411-414.

Keane TM, Goodstadt L, Danecek P, White MA, Wong K, Yalcin B, Heger A Agam A, Slater G, Goodson M, et al. 2011. Mouse genomic variation and its effect on phenotypes and gene regulation. Nature 477: 289-294.

Li Z, Mulligan MK, Wang X, Miles MF, Lu L, Williams RW. 2010. A transposon in Comt generates mRNA variants and causes widespread expression and behavioral differences among mice. PLOS ONE 5: e12181. doi: 10.1371/journal.pone.0012181.

Lin F, Worman HJ. 1993. Structural organization of the human gene encoding nuclear lamin A and nuclear lamin C. J Biol Chem 268: 16321-16326.

Lueders KK, Frankel WN, Mietz JA, Kuff EL. 1993. Genomic mapping of intracisternal A-particle proviral elements. Mamm Genome 4: 69-77.

Macfarlan TS, Gifford WD, Agarwal S, Driscoll S, Lettieri K, Wang J, Andrews SE, Franco L, Rosenfeld MG, Ren B, et al. 2011. Endogenous retroviruses and neighboring genes are coordinately repressed by LSD1/KDM1A. Genes Dev 25: 594-607.

Medstrand P, van de Lagemaat LN, Mager DL. 2002. Retroelement distributions in the human genome: Variations associated with age and proximity to genes. Genome Res 12: 1483-1495.

Medstrand P, van de Lagemaat LN, Dunn CA, Landry JR, Svenback D, Mager DL. 2005. Impact of transposable elements on the evolution of mammalian gene regulation. Cytogenet Genome Res 110: 342-352.

Mikkelsen TS, Ku M, Jaffe DB, Issac B, Lieberman E, Giannoukos G, Alvarez P, Brockman W, Kim TK, Koche RP, et al. 2007. Genome-wide maps of chromatin state in pluripotent and lineage-committed cells. Nature 448: $553-560$.

Monk D, Arnaud P, Frost JM, Wood AJ, Cowley M, Martin-Trujillo A, Guillaumet-Adkins A, Iglesias Platas I, Camprubi C, Bourc'his D, et al. 2011. Human imprinted retrogenes exhibit non-canonical imprint chromatin signatures and reside in non-imprinted host genes. Nucleic Acids Res 39: 4577-4586.

Morgan HD, Sutherland HG, Martin DI, Whitelaw E. 1999. Epigenetic inheritance at the agouti locus in the mouse. Nat Genet 23: 314-318.

Morrissy AS, Griffith M, Marra MA. 2011. Extensive relationship between antisense transcription and alternative splicing in the human genome. Genome Res 21: 1203-1212.

Mural RJ, Adams MD, Myers EW, Smith HO, Miklos GL, Wides R, Halpern A, Li PW, Sutton GG, Nadeau J, et al. 2002. A comparison of whole-genome shotgun-derived mouse chromosome 16 and the human genome. Science 296: 1661-1671.

Ocheltree SM, Shen H, Hu Y, Keep RF, Smith DE. 2005. Role and relevance of peptide transporter 2 (PEPT2) in the kidney and choroid plexus: In vivo studies with glycylsarcosine in wild-type and PEPT2 knockout mice. J Pharmacol Exp Ther 315: 240-247.

Peaston AE, Evsikov AV, Graber JH, de Vries WN, Holbrook AE, Solter D, Knowles BB. 2004. Retrotransposons regulate host genes in mouse oocytes and preimplantation embryos. Dev Cell 7: 597-606.

Pornthanakasem W, Mutirangura A. 2004. LINE-1 insertion dimorphisms identification by PCR. BioTechniques 37: 750-752

Qin C, Wang Z, Shang J, Bekkari K, Liu R, Pacchione S, McNulty KA, Ng A, Barnum JE, Storer RD. 2010. Intracisternal A particle genes: Distribution in the mouse genome, active subtypes, and potential roles as speciesspecific mediators of susceptibility to cancer. Mol Carcinog 49: 54-67.

Rakyan VK, Chong S, Champ ME, Cuthbert PC, Morgan HD, Luu KV, Whitelaw E. 2003. Transgenerational inheritance of epigenetic states at the murine $\mathrm{Axin}^{\mathrm{Fu}}$ allele occurs after maternal and paternal transmission. Proc Natl Acad Sci 100: 2538-2543. 
Ray A, Rahbari R, Badge RM. 2011. IAP display: A simple method to identify mouse strain specific IAP insertions. Mol Biotechnol 47: 243-252.

Rebollo R, Karimi MM, Bilenky M, Gagnier L, Miceli-Royer K, Zhang Y, Goyal P, Keane TM, Jones S, Hirst M, et al. 2011. Retrotransposon-induced heterochromatin spreading in the mouse revealed by insertional polymorphisms. PLoS Genet 7: e1002301. doi: 10.1371/ journal.pgen.1002301.

Salem AH, Ray DA, Batzer MA. 2005. Identity by descent and DNA sequence variation of human SINE and LINE elements. Cytogenet Genome Res $\mathbf{1 0 8}$ 63-72.

Schlattl A, Anders S, Waszak SM, Huber W, Korbel JO. 2011. Relating CNVs to transcriptome data at fine resolution: Assessment of the effect of variant size, type, and overlap with functional regions. Genome Res 21: 2004-2013.

Seperack PK, Mercer JA, Strobel MC, Copeland NG, Jenkins NA. 1995. Retroviral sequences located within an intron of the dilute gene alter dilute expression in a tissue-specific manner. EMBO J 14: 2326-2332.

She X, Cheng Z, Zollner S, Church DM, Eichler EE. 2008. Mouse segmental duplication and copy number variation. Nat Genet 40: 909-914.

Shen H, Smith DE, Keep RF, Xiang J, Brosius FC III. 2003. Targeted disruption of the PEPT2 gene markedly reduces dipeptide uptake in choroid plexus. I Biol Chem 278: 4786-4791.

Shen H, Ocheltree SM, Hu Y, Keep RF, Smith DE. 2007. Impact of genetic knockout of PEPT2 on cefadroxil pharmacokinetics, renal tubular reabsorption, and brain penetration in mice. Drug Metab Dispos 35: 1209-1216.

Shen-Ong GL, Cole MD. 1982. Differing populations of intracisternal Aparticle genes in myeloma tumors and mouse subspecies. J Virol 42: 411-421.

Smit AF. 1999. Interspersed repeats and other mementos of transposable elements in mammalian genomes. Curr Opin Genet Dev 9: 657-663.

Smith DE, Hu Y, Shen H, Nagaraja TN, Fenstermacher JD, Keep RF. 2011. Distribution of glycylsarcosine and cefadroxil among cerebrospinal fluid, choroid plexus, and brain parenchyma after intracerebroventricular injection is markedly different between wildtype and Pept2 null mice. I Cereb Blood Flow Metab 31: 250-261.

Stoye JP, Fenner S, Greenoak GE, Moran C, Coffin JM. 1988. Role of endogenous retroviruses as mutagens: The hairless mutation of mice. Cell 54: 383-391.

Suzuki S, Ono R, Narita T, Pask AJ, Shaw G, Wang C, Kohda T, Alsop AE, Marshall Graves JA, Kohara Y, et al. 2007. Retrotransposon silencing by DNA methylation can drive mammalian genomic imprinting. PLoS Genet 3: e55. doi: 10.1371/journal.pgen.0030055.

Takabatake T, Ishihara H, Ohmachi Y, Tanaka I, Nakamura MM, Fujikawa K, Hirouchi T, Kakinuma S, Shimada Y, Oghiso Y, et al. 2008. Microarraybased global mapping of integration sites for the retrotransposon, intracisternal A-particle, in the mouse genome. Nucleic Acids Res 36: e59. doi: $10.1093 / \mathrm{nar} / \mathrm{gkn} 235$.

Tan-Wong SM, French JD, Proudfoot NJ, Brown MA. 2008. Dynamic interactions between the promoter and terminator regions of the mammalian BRCA1 gene. Proc Natl Acad Sci 105: 5160-5165.

van de Lagemaat LN, Landry JR, Mager DL, Medstrand P. 2003. Transposable elements in mammals promote regulatory variation and diversification of genes with specialized functions. Trends Genet 19: 530-536. van de Lagemaat LN, Medstrand P, Mager DL. 2006. Multiple effects govern endogenous retrovirus survival patterns in human gene introns. Genome Biol 7: R86. doi: 10.1186/gb-2006-7-9-r86.

Wade CM, Daly MJ. 2005. Genetic variation in laboratory mice. Nat Genet 37: $1175-1180$.

Walsh CP, Chaillet JR, Bestor TH. 1998. Transcription of IAP endogenous retroviruses is constrained by cytosine methylation. Nat Genet 20: 116-117.

Wang ET, Sandberg R, Luo S, Khrebtukova I, Zhang L, Mayr C, Kingsmore SF, Schroth GP, Burge CB. 2008. Alternative isoform regulation in human tissue transcriptomes. Nature 456: 470-476.

Waterston RH, Lindblad-Toh K, Birney E, Rogers J, Abril JF, Agarwal P, Agarwala R, Ainscough R, Alexandersson M, An P, et al. 2002. Initial sequencing and comparative analysis of the mouse genome. Nature 420: $520-562$.

Wheelan SJ, Aizawa Y, Han JS, Boeke JD. 2005. Gene-breaking: A new paradigm for human retrotransposon-mediated gene evolution. Genome Res 15: 1073-1078.

Whitelaw E, Martin DI. 2001. Retrotransposons as epigenetic mediators of phenotypic variation in mammals. Nat Genet 27: 361-365.

Wilusz JE, Spector DL. 2010. An unexpected ending: Noncanonical 3' end processing mechanisms. RNA 16: 259-266.

Witherspoon DJ, Xing J, Zhang Y, Watkins WS, Batzer MA, Jorde LB. 2010. Mobile element scanning (ME-Scan) by targeted high-throughput sequencing. BMC Genomics 11: 410. doi: 10.1186/ 1471-2164-11-410.

Wood AJ, Schulz R, Woodfine K, Koltowska K, Beechey CV, Peters J, Bourc'his D, Oakey RJ. 2008. Regulation of alternative polyadenylation by genomic imprinting. Genes Dev 22: 1141-1146.

Wu TD, Watanabe CK. 2005. GMAP: A genomic mapping and alignment program for mRNA and EST sequences. Bioinformatics 21: 1859-1875.

Yalcin B, Wong K, Agam A, Goodson M, Keane TM, Gan X, Nellaker C, Goodstadt L, Nicod J, Bhomra A, et al. 2011. Sequence-based characterization of structural variation in the mouse genome. Nature 477: 326-329.

Yan J, Marr TG. 2005. Computational analysis of 3'-ends of ESTs shows four classes of alternative polyadenylation in human, mouse, and rat. Genome Res 15: 369-375.

Yan H, Yuan W, Velculescu VE, Vogelstein B, Kinzler KW. 2002. Allelic variation in human gene expression. Science 297: 1143.

Yang H, Bell TA, Churchill GA, Pardo-Manuel de Villena F. 2007. On the subspecific origin of the laboratory mouse. Nat Genet 39: 1100-1107.

Zhang Y, Maksakova IA, Gagnier L, van de Lagemaat LN, Mager DL. 2008. Genome-wide assessments reveal extremely high levels of polymorphism of two active families of mouse endogenous retroviral elements. PLoS Genet 4: e1000007. doi: 10.1371/journal.pgen.1000007.

Zhou W, Bouhassira EE, Tsai HM. 2007. An IAP retrotransposon in the mouse ADAMTS13 gene creates ADAMTS13 variant proteins that are less effective in cleaving von Willebrand factor multimers. Blood 110: 886-893.

Received August 16, 2011; accepted in revised form February 9, 2012. 


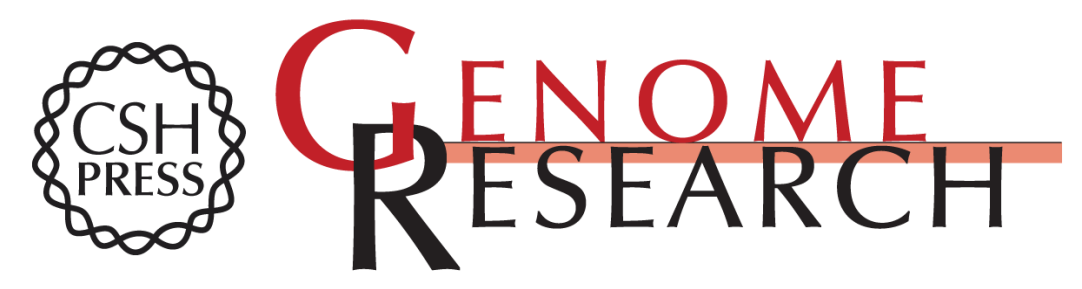

\section{Mouse endogenous retroviruses can trigger premature transcriptional termination at a distance}

Jingfeng Li, Keiko Akagi, Yongjun Hu, et al.

Genome Res. 2012 22: 870-884 originally published online February 23, 2012

Access the most recent version at doi:10.1101/gr.130740.111

Supplemental Material

References

Creative

Commons

License

Email Alerting

Service
http://genome.cshlp.org/content/suppl/2012/02/10/gr.130740.111.DC1

This article cites 73 articles, 24 of which can be accessed free at: http://genome.cshlp.org/content/22/5/870.full.html\#ref-list-1

This article is distributed exclusively by Cold Spring Harbor Laboratory Press for the first six months after the full-issue publication date (see

$\mathrm{http}: / / g$ enome.cshlp.org/site/misc/terms.xhtml). After six months, it is available under a Creative Commons License (Attribution-NonCommercial 3.0 Unported License), as described at http://creativecommons.org/licenses/by-nc/3.0/.

Receive free email alerts when new articles cite this article - sign up in the box at the top right corner of the article or click here.

\section{Affordable, Accurate Sequencing.}

To subscribe to Genome Research go to:

https://genome.cshlp.org/subscriptions 